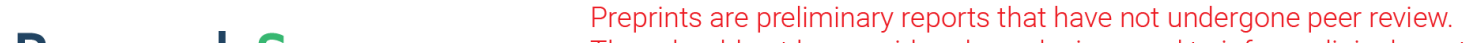 They should not be considered conclusive, used to inform clinical practice, or referenced by the media as validated information. \\ Experimental and Theoretical Approach of Evaluating Chitosan Ferulic Acid Amide As An Effective Corrosion Inhibitor
}

Hepziba Magie Jessima S.J ( $\square$ hepziba.magie@christuniversity.in )

Christ University

\section{S. Subhashini}

Avinashilingam Institute of Home Science and Higher Education for Women: Avinashilingam University for Women

\section{Avni Berisha}

Universiteti i Prishtinës: Universiteti i Prishtines Hasan Prishtina

\section{Valbonë Mehmeti}

Universiteti i Prishtinës: Universiteti i Prishtines Hasan Prishtina

\section{Subramanian Sathy Srikandan}

PSG College of Technology

\section{Research Article}

Keywords: a. Modified chitosan, b. mild steel, c. corrosion inhibitors, d. EIS, and e. Monte Carlo and molecular dynamic simulation

Posted Date: February 11th, 2021

DOl: https://doi.org/10.21203/rs.3.rs-161633/v1

License: (9) This work is licensed under a Creative Commons Attribution 4.0 International License. Read Full License 
Experimental and theoretical approach of evaluating chitosan ferulic acid amide as an effective corrosion inhibitor

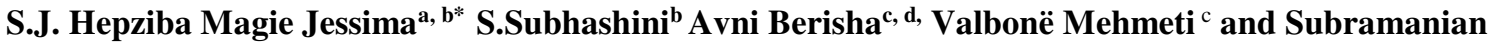 \\ Sathy Srikandan ${ }^{\mathrm{d}}$ \\ ${ }^{a}$ Department of Chemistry, CHRIST (Deemed to be University), Bengaluru-560029, India \\ ${ }^{b}$ Department of Chemistry, Avinashilingam Institute for Home Science and Higher Education for Women \\ (Deemed to be University), Coimbatore-641043, India \\ ${ }^{\mathrm{c}}$ Chemistry Department of Natural Sciences Faculty, University of Prishtina, rr. "NënaTereze" nr.5, 10000, \\ Prishtina, Kosovo \\ ${ }^{\mathrm{d}}$ Materials Science - Nanochemistry Research Group, NanoAlb - Unit of Albanian Nanoscience and \\ Nanotechnology, Tirana, Albania. \\ e'Department of Applied Science, PSG COLLEGE OF TECHNOLOGY, Peelamedu, Coimbatore-641004
}

\begin{abstract}
Phenolic acid grafted chitosan has widespread drug delivery applications, as bio adsorbent, packing material, etc., due to its excellent antioxidant and antimicrobial properties. However, for the first time, the anticorrosive efficiency of ferulic acid modified chitosan has been investigated. The prepared chitosan derivative is characterized using spectral methods, thermal analytical methods, surface charge, and particle size analysis. The evaluation of corrosion inhibition potential showed a highest value of $95.96 \%$ at $303 \mathrm{~K}$. Thermodynamic activation and adsorption parameters endorse a mixed adsorption process involving an initial electrostatic interaction followed by chemisorption. Electrochemical studies gave results which agreed well with the gravimetric studies. Surface morphological studies were performed using contact angle measurements, FESEM, EDAX, AFM, optical profilometric and UV spectral techniques. Computational studies involving quantum chemical calculations, Monte Carlo and molecular dynamic simulation studies, and radial distribution function analysis are further done to validate the experimental results.
\end{abstract}

Keywords: a. Modified chitosan, b. mild steel, c. corrosion inhibitors, d. EIS, and e. Monte Carlo and molecular dynamic simulation

*Corresponding author. E-mail address: hepziba.magie@christuniversity.in 
Highlights

39

* Chitosan ferulic acid amide was evaluated for corrosion inhibition performance

40

I.E of the modified chitosan was found to be $95.96 \%$ for mild steel in $1 \mathrm{M} \mathrm{HCl}$

41

* Adsorption process obeyed Langmuir isotherm further supported by $\mathrm{K}_{\mathrm{L}}$ factor

42

* Good correlation of experimental results from weight loss and electrochemical studies

43

* Experimental results validated by theoretical studies

44

45

46

47

48

49

50

51

52

53

54

55

56

57

58

59

60

61

62

63

64

65

66 
68

69

70

71

72

73

74

75

76

77

78

79

80

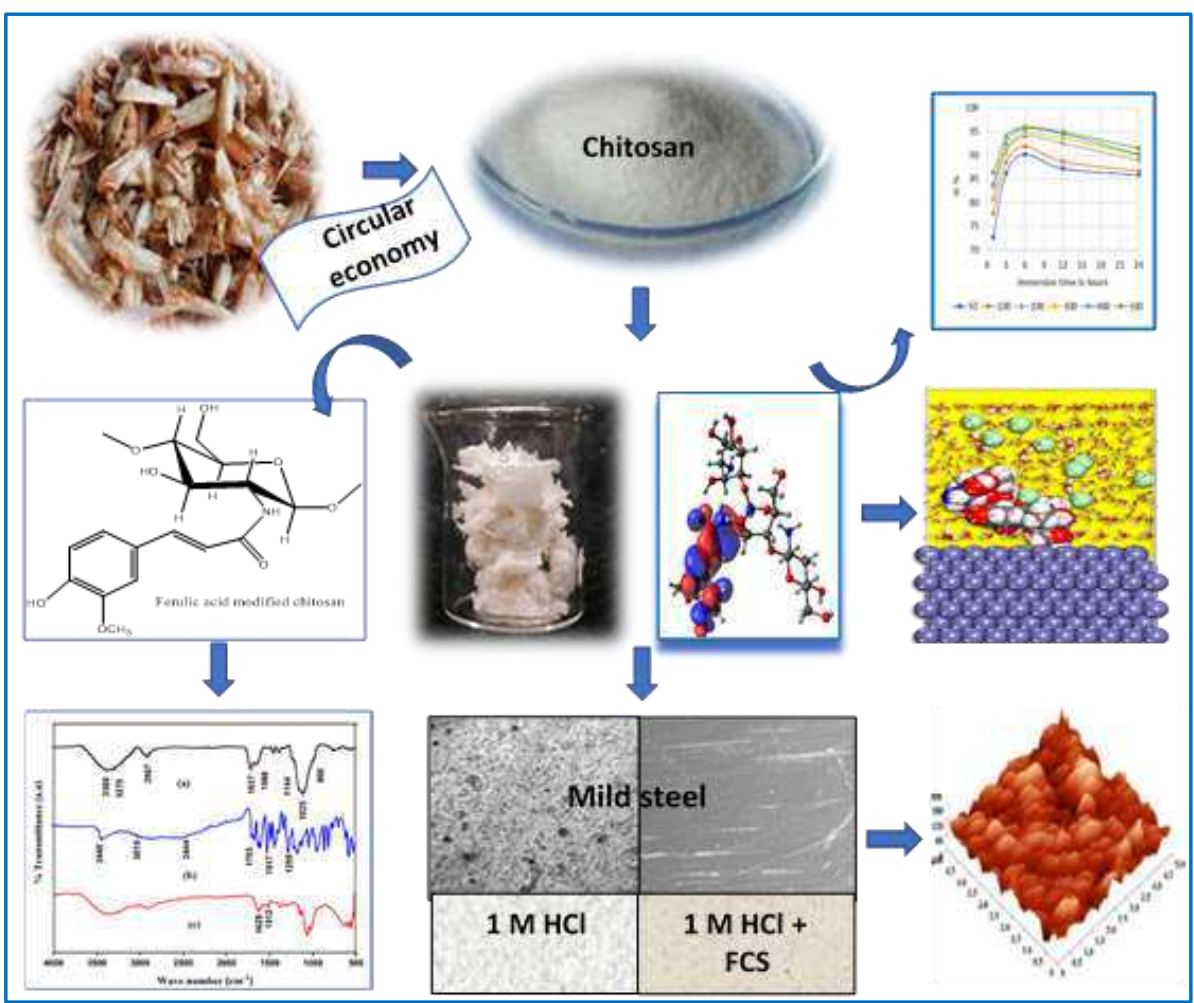

81

82

83

84

85

86

87

88

89

90

91

92

93

94 


\section{INTRODUCTION}

The acid treatment of metals, namely acid pickling, descaling, etching, etc., renders the metal surface free from stain, scale, rust, and other impurities. However, this action exposes the clean, bare metal more to the aggressive medium resulting in an increased metal dissolution. Therefore, corrosion inhibitors are used as additives in the cleaning acids. These additives mitigate corrosion by adsorbing themselves on the metal surface, forming a protective film that prevents the metal surface from being exposed to the aggressive environment (Sherif 2014). The use of inhibitors is economical and compatible compared to other mitigation techniques. Besides, it allows the use of low-grade carbon steel in the place of high-cost alloys (Finšgar and Jackson 2014). There are numerous corrosion inhibitors tested and proven, but only a few are employed in practice. This observation reveals that in addition to protection, certain other factors such as cost-effectiveness, eco-friendly, non-toxic nature, ready availability, and compatibility in combating corrosion also matters. Polymers can act as effective corrosion inhibitors due to their inherent stability, ability to form complexes that can blanket the metal surface, and multiple binding sites that help in slower desorption.

Many of the natural polymers such as natural gums (Peter et al. 2015; Mobin et al. 2017), pectin (Fares et al. 2012b; Fiori-Bimbi et al. 2015; Umoren et al. 2015), derivatives of cellulose (Solomon et al. 2010; Li et al. 2015; Sangeetha et al. 2016; Umoren et al. 2018), starch (Zulhusni et al. 2015; Charitha and Rao 2017; Parveen et al. 2018), carrageen (Khairou et al. 2007; Fares et al. 2012a), alginates (Obot et al. 2017; Jmiai et al. 2018), and chitosan (Waanders et al. 2002; El-Haddad 2013; Umoren et al. 2013; Gupta et al. 2018; Brou et al. 2020) are evaluated as potential corrosion inhibitors for different metals in acidic and neutral solutions. However, some polymers show low solubility in aqueous solutions and undergo decomposition at higher temperatures (Solomon et al. 2017). Modification of the biopolymers was found to improve the solubility and increase the adsorption sites in the polymer. The literature survey also reveals the various attempts to relate the antioxidant properties with that of the anticorrosive behavior in different plant extracts and organic compounds. This survey was done to analyze whether antioxidative properties can serve as a predictive index to evaluate the corrosion inhibition efficiency ( $\mathrm{V}$ V Sher and Voevoda; Boujakhrout et al. 2015; Hussin et al. 2015; Júnior et al. 2016; Momin et al. 2016; Prabakaran et al. 2019; Vorobyova et al. 2019). Therefore, the present investigation targets the preparation of a water-soluble corrosion inhibitor with excellent antioxidant properties. By employing chitosan from the seafood waste, the dire need of the hour, namely practicing circular economy, has been realized in this research work.

Chitosan has poly hydroxyl and amine groups that make it an efficient functional material exploited in various applications (Kumar 2000). Studies on chitosan and its derivatives reveal its efficacy as potential green corrosion inhibitors. Polyaniline chitosan demonstrated a corrosion inhibition efficiency of $84.78 \%$ for $\mathrm{Q}_{235}$ mild steel in the acid medium (Kong et al. 2019). PEG crosslinked chitosan showed an excellent corrosion inhibition efficiency of $93.9 \%$ for mild steel in sulphamic acid (Chauhan et al. 2018b). Amylose acetate blended carboxymethyl chitosan records an anticorrosive potential of $97.65 \%$ against mild steel in the acid medium (Erna et al. 2019). Chitosan-based thiosemicarbazide, thiocarbohydrazide, and Schiff bases also proved to be efficient green corrosion inhibitors (Menaka and Subhashini 2016; Chauhan et al. 2018a). Chitosan derivatives are proved to be excellent corrosion mitigators of other metals also (Mohamed and Fekry 2011; Giuliani et al. 2018)

In the present investigation, ferulic acid modified chitosan (FCS) was prepared using the method reported earlier (Woranuch and Yoksan 2013) with slight modification and was characterized using different techniques. FCS plays a significant role in several biomedical applications, and for the first time, its application in the field 
of corrosion is explored in the present study. The corrosion mitigation efficiency of FCS was assessed using the gravimetric method and electrochemical studies. Surface studies serve as evidence for the mitigation potential of the inhibitor (Jessima et al. 2020a). Theoretical studies were done to validate the experimental results.

\section{EXPERIMENTAL}

\subsection{Instrumentation}

The functional group characterization of FCS was done using ATR-FTIR (Shimadzu IRSpirit), UVvisible (Shimadzu UV-1800), and proton NMR (Bruker 400 MHz NMR) spectral studies. Thermogravimetric and differential scanning calorimetric curves were recorded (STA-6000 from Perkin Elmer) to analyze the temperature response. Malvern Zeta sizer (ZEN 3600) was employed to study the particle charge and size analysis.

Gamry Reference - 600 instrument was employed for the electrochemical studies and Echemanalyst software for interpreting the experimental results

Surface morphology studies of the metal samples were done to relate the decrease in metal dissolution with the inhibitor film formation. The contact angle analyzer, Phoenix 300 Plus model, was used for the contact angle measurement. Carl Zeiss Sigma V Field Emission Scanning Electron Microscope was employed for SEM and EDAX analyses. Atomic force microscope (NTDMT model) and optical profilometer (ZETA-20 model), engaged for surface topography and roughness studies. Images in the optical profilometer captured using a 20x magnification lens. Zeta 3D software is used for the analysis of the images.

\subsection{Chemicals and reagents}

Chitosan (75\% deacetylated) and ferulic acid (minimum assay of 99.0\%) were procured from Hi-Media Laboratories Pvt. Ltd. The carbodiimide coupling reagent (EDC) and doubly distilled water were procured from Sisco Research Laboratories Pvt. Ltd. Analar grade concentrated hydrochloric acid, acetone, ethanol, methanol were used for the investigation. Chitosan was further washed with boiling water, followed by methanol, and dried in a vacuum desiccator (Giuliani et al. 2018).

\subsection{Mild steel metal samples}

Mild steel samples were cut into strips of $5 \times 1 \times 0.2 \mathrm{~cm}$ dimension and $1 \times 1 \mathrm{~cm}$ dimension for weight loss and electrochemical studies. The metal samples were polished with a buff wheel, abraded with fine emery sheets, cleaned, and degreased before storing in the desiccator for further use.

\subsection{Preparation of corrosion inhibitor}

Chitosan in $25 \mathrm{ml}$ of $0.25 \mathrm{M}$ hydrochloric acid was stirred overnight at room temperature. An equal amount of ferulic acid is added to the EDC coupling reagent in $10 \mathrm{ml}$ of absolute ethanol. The mixture is then slowly transferred to the chitosan solution placed on a magnetic stirrer maintained at $60{ }^{\circ} \mathrm{C}$. The stirring was continued for 3 hours, and the white precipitate obtained was washed with acetone, then kept in a desiccator for drying. Scheme I display the chemical reaction involved in the preparation of the modified chitosan.

Scheme I Preparation of FCS

\subsection{Assessment of anticorrosive performance of FCS}

\subsubsection{Gravimetric studies}

Preweighed metal samples in triplicates were held in suitable glass hooks and immersed in $100 \mathrm{ml}$ beakers containing 0 to 500 ppm concentration of FCS inhibitor in $1 \mathrm{M} \mathrm{HCl}$ (Jessima et al. 2020b). The immersion 
periods chosen for the present study include $1 / 2,1,3,6,12$, and 24 hours at $303 \mathrm{~K}$. After the stipulated immersion periods, the samples were removed, washed thoroughly with water, and placed in the desiccator. The metal samples are weighed again to note the weight loss. The same procedure was repeated for the temperature studies done at $303,313,323,333$, and $343 \mathrm{~K}$ for an immersion period of half an hour. Both the immersion and temperature studies were performed in triplicates under aerated and unstirred conditions.

The inhibition efficiency $\left(\eta_{C I}\right)$ of FCS against corrosion was calculated using eq. 1 and corrosion rate $\left(K_{C R}\right)$ using eq. 2.

$$
\begin{aligned}
& \eta_{\mathrm{CI}}=\frac{W b-W i}{W b} \times 100 \text {-------------------eq.1} \\
& K_{C R}(m p y)=\frac{3.45 * 10^{6} * \text { weight loss }}{D A T}
\end{aligned}
$$

where $\mathrm{w}_{\mathrm{b}}$ and $\mathrm{w}_{\mathrm{i}}$ represent the weight loss of the metal samples when exposed to $1 \mathrm{M}$ hydrochloric acid and FCS solution, respectively. $D$ is the metal density in $\mathrm{g} / \mathrm{cm}^{3}, A$ is the area of the metal samples in $\mathrm{cm}^{2}$ and $\mathrm{T}$ indicates the exposure period in hours.

\subsubsection{DC and AC electrochemical measurements}

Tafel, linear polarization resistance, and AC impedance studies were carried out at room temperature under aerated and unstirred conditions using Gamry Reference 600 instrument. Mild steel sample was employed as the working electrode, stable and robust saturated calomel electrode as reference electrode, and platinum electrode as an auxiliary to complete the cell circuit. The electrochemical impedance spectroscopic studies were performed at a frequency range of $100 \mathrm{kHz}$ to $0.01 \mathrm{~Hz}$ with $10 \mathrm{mV}$ amplitude as AC signal at steady state open circuit potential. Echemanalyst software interpreted the experimental results. Tafel polarization curves were obtained by applying a sweeping potential of $+250 \mathrm{mV}$ anodically and $-250 \mathrm{mV}$ cathodically versus the open circuit potential at $0.1666 \mathrm{mV} / \mathrm{sec}$ scan rate. The linear polarization resistance measurements were made at \pm 20 $\mathrm{mV}$ vs. OCP and $0.5 \mathrm{mV} / \mathrm{sec}$ scan rate (Jafar Mazumder 2019; Kartsonakis et al. 2020).

The percentage of inhibition efficiency of the FCS inhibitor is calculated using $i_{\text {corr }}$ values from Tafel studies, LPR values from linear polarisation studies, and $R_{p}$ values from impedance studies employing the following equations

where $\quad I \operatorname{Icorr}_{0}$ and $I \operatorname{Icorr}_{\text {inh }}, L P R_{0}$ and $L P R_{\text {inh }}, R p_{0}$ and $R p_{\text {inh }}$ represent the corrosion current density, linear polarisation resistance, and polarization resistance obtained when the electrolyte solution was $1 \mathrm{M} \mathrm{HCl}$ and FCS, respectively

\subsection{Theoretical studies}

\subsubsection{Quantum chemical calculations}

Quantum chemical calculations were done using density functional theory employing Gaussian 09 software in the framework of the B3LYP/6-31+G $(d, p)$ basis set. Theoretical parameters were calculated for the optimized molecular geometry of neutral and protonated FCS. The Mulliken charges generated aided to locate the site of protonation, which has the highest negative charge. According to Koopman's theorem, the following 
According to Mulliken, the electronegativity $(\chi)$ is the average value of ionization potential and electron affinity

$$
\chi=\frac{I+A}{2}
$$

Similarly, the global hardness $(\eta)$ is calculated using the eq. 9.

$$
\eta=\frac{I-A}{2}
$$

$\eta$ is related to the energy gap between the frontier molecular orbitals. The lesser the energy gap, the more is the softness, and the greater is its chemical reactivity.

According to Parr et al., the electrophilicity index $(\omega)$ is the natural tendency of a species to accept electrons. The electrophilicity index $(\omega)$ can be calculated using the eq.10

$$
\omega=\frac{\chi^{2}}{4 \eta}
$$

The quantum parameter $\Delta \mathrm{N}$ is used to evaluate the altitude of the transferred electrons and represented by the following equation

$$
\Delta \mathrm{N}=\frac{\phi_{F e}-\chi_{i n h}}{2\left(\eta_{F e}+\eta_{i n h}\right)}
$$

where $\phi_{F e}$ refers to the electronegativity of $\mathrm{Fe}$, and its theoretical value is $4.82 \mathrm{eV}$ for (110) plane chosen because of the higher stabilization energy. The value of $\eta_{F e}$ is equal to zero (Dagdag et al. 2019a).

\subsubsection{Monte Carlo and Molecular Dynamic simulation details}

The evaluation of the interaction between the Fe (110) surface and the inhibitor molecule (FCS) throughout Monte Carlo (MC) and Molecular dynamic (MD) simulation is performed in the simulated corrosion medium by the use of a seven atom-thick layer unit cell of Fe (110) surface. The slab size used in these calculations was: $24.842 \AA$ x $24.842 \AA$ x $12.533 \AA$ with a $25 \AA$ vacuum layer. This box is filled with 550 water molecules/1 inhibitor molecule (in neutral or protonated state) / 10 hydronium +10 chloride ions (Faydy et al. 2020).

MD was attained using the NVT at $298 \mathrm{~K}$ over a simulation time of 300 ps (using a $1 \mathrm{fs}$ time step and 0.5 ns simulation time) (Hsissou et al. 2019b, 2020b, a; Dagdag et al. 2020d, a). The temperature control is attained via the Berendsen thermostat (Dagdag et al. 2020e). The recurrently COMPASSII forcefield used in corrosion studies was used for the MC (Monte Carlo) and MD (Molecular Dynamic) (Sun et al. 2016; Berisha 2019; Dagdag et al. 2020b; Abbout et al. 2020). The Radial Distribution Function (RDF) analysis is implemented on the complete trajectory of the MD [38,52].

\section{RESULTS AND DISCUSSION}

\subsection{Spectral characterization, thermal stability, and zeta potential analysis of FCS}

Comparative infrared spectra of (a) chitosan biopolymer, (b) ferulic acid, and (c) FCS is displayed in Fig 1. The chitosan spectrum shows absorption bands at $3270-368 \mathrm{~cm}^{-1}$ arising due to $\mathrm{N}-\mathrm{H}$ and $\mathrm{O}-\mathrm{H}$ stretching vibrations. This band also includes intramolecular hydrogen bond characteristic of polysaccharides. The symmetric and asymmetric stretching of $\mathrm{C}-\mathrm{H}$ bonds occur at 2911 and $2867 \mathrm{~cm}^{-1}$. The $\mathrm{C}=\mathrm{O}$ and $\mathrm{C}-\mathrm{N}$ stretching vibrations of the $\mathrm{N}$-acetyl group are found at $1637 \mathrm{~cm}^{-1}$ and $1317 \mathrm{~cm}^{-1}$. The absorbance band found at $1568 \mathrm{~cm}^{-1}$ is due to $\mathrm{N}-\mathrm{H}$ bending vibrations of the primary amine. $\mathrm{CH}_{2}$ bending vibrations and $\mathrm{CH}_{3}$ symmetrical deformations are identified at $1420 \mathrm{~cm}^{-1}$ and $1381 \mathrm{~cm}^{-1}$, respectively. IR peaks at $1144 \mathrm{~cm}^{-1}, 1059 \mathrm{~cm}^{-1}$ and $1025 \mathrm{~cm}^{-1}$ corresponds 
to the C-O-C bridge and $\mathrm{C}-\mathrm{O}$ asymmetric stretching. The $\mathrm{C}-\mathrm{H}$ bending vibrations of out of plane of the monosaccharide ring correspond to the peak at $900 \mathrm{~cm}^{-1}$ (Queiroz et al. 2015). Ferulic acid has the following characteristic peaks, namely $\mathrm{O}-\mathrm{H}$ stretching at $3448 \mathrm{~cm}^{-1}$ and $\mathrm{C}-\mathrm{H}$ stretching at $2911-3015 \mathrm{~cm}^{-1}, \mathrm{C}=\mathrm{O}$ stretching of the carboxyl group at $1703 \mathrm{~cm}^{-1}, \mathrm{C}=\mathrm{C}$ of the aromatic ring at $1517 \mathrm{~cm}^{-1}$, and $\mathrm{C}-\mathrm{O}$ stretching of the carboxylic group at $1272 \mathrm{~cm}^{-1}$ (Almeida et al. 2018). The new peak at $1512 \mathrm{~cm}^{-1}$ corresponds to $\mathrm{C}=\mathrm{C}$ of the aromatic ring that serves as evidence for FCS formation. The intensity of $\mathrm{C}=\mathrm{O}$ and $\mathrm{N}-\mathrm{H}$ stretching bands of the amide group found at $1625 \mathrm{~cm}^{-1}$, and $1553 \mathrm{~cm}^{-1}$ is also increased. The increased peak intensity at $2926 \mathrm{~cm}^{-1}$ can be attributed to $\mathrm{C}-\mathrm{H}$ stretching. The disappearance of the N-H absorption peak of the primary amine at $1589 \mathrm{~cm}^{-1}$ further supports the grafting process (Woranuch and Yoksan 2013; Li and Li 2017). There is no IR peak at $1730 \mathrm{~cm}^{-1}$ that confirms the absence of ester formation.

Fig 1 Comparative IR spectrum of (a) Chitosan biopolymer (b) Ferulic acid and (c) FCS

Fig 2 displays the UV visible spectra of chitosan biopolymer, ferulic acid, and FCS. Chitosan in $1 \%$ acetic acid is found to give no absorption peak in the entire spectral range from $250 \mathrm{~nm}$ to $400 \mathrm{~nm}$. An ethanolic solution of ferulic acid shows an absorbance maximum at $290 \mathrm{~nm}$ and $321 \mathrm{~nm}$. FCS in $1 \mathrm{M} \mathrm{HCl}$ solution shows the same absorbance maxima at $321 \mathrm{~nm}$ that supports chitosan ferulic acid amide (Woranuch and Yoksan 2013; Chatterjee et al. 2016). Some literature studies also have highlighted redshift for ferulic acid grafted chitosan (Liu et al. 2017)

Fig 2 Comparative UV spectrum of (a) Chitosan, (b) Ferulic acid, and (c) FCS

The chemical structure of the FCS inhibitor is further characterized using $\mathrm{H}^{1}$ NMR spectra portrayed in Fig 3. The $\mathrm{D}_{2} \mathrm{O}$ solvent peak is found at $4.8 \mathrm{ppm}$, and the proton signals at $3.8 \mathrm{ppm}, 6.3 \mathrm{ppm}$, and $7.6 \mathrm{ppm}$ correspond to $-\mathrm{OCH}_{3}$ and methine protons $\mathrm{CH}(\mathrm{g}), \mathrm{CH}$ (h) of ferulic acid, respectively. The remaining aromatic protons, namely $\mathrm{H}_{(\mathrm{e}-\mathrm{f})}$, show doublet signals at $7.1 \mathrm{ppm}, 6.8 \mathrm{ppm}$, and $7.2 \mathrm{ppm}$. The proton signals at $5.2 \mathrm{ppm}$, 3.18 ppm, 3.7- 4.5 ppm correspond to chitosan protons $\mathrm{H}_{(1-6)}$ (Woranuch and Yoksan 2013).

Fig 3 NMR spectrum of FCS inhibitor

Comparative TGA and DSC curves of chitosan and FCS are shown in Fig.S1 (a) and (b), respectively. TGA curve of chitosan reflects a weight loss of $50 \%$ at the degradation temperature range of $295-370{ }^{\circ} \mathrm{C}$, whereas that of the modified polymer is $209-302{ }^{\circ} \mathrm{C}$. The thermal stability of FCS is reduced compared to chitosan biopolymer. The decrease may be accounted due to the loose packing structure or reduction in the intermolecular hydrogen bonding (Liu et al. 2014; Li and Li 2017). DSC curve of chitosan shows a broad endothermic peak at $122{ }^{\circ} \mathrm{C}$ that corresponds to the loss of moisture content bound to the polymeric backbone. The exothermic peak at $337{ }^{\circ} \mathrm{C}$ is attributed to the decomposition of chitosan. In contrast, the endothermic and exothermic peaks of FCS are found at lower temperatures than chitosan, i.e., at $114{ }^{\circ} \mathrm{C}$ and $210{ }^{\circ} \mathrm{C}$, respectively (Woranuch and Yoksan 2013).

Fig S2 (a) and (b) reveals the zeta potential value and the average particle diameter distribution of FCS are $+49.5 \mathrm{mV}$ and $383.3 \mathrm{~nm}$, respectively. Polymers with a zeta potential value greater than $30 \mathrm{mV}$ can show a more stable dispersion as the particles repel each other (Rahman et al. 2018)(Elbasuney et al. 2019). Corrosion inhibitors with a positive zeta potential value can enhance corrosion protection. The positive surface charge on the inhibitor thus serves in adhering to the oxidized metal surface through the anions of the acid solution (Huffer et al). 


\subsection{Measurement of the anticorrosive performance of FCS}

\subsubsection{Gravimetric studies}

Fig.4 (a) portrays the change in the inhibition efficiency of FCS with varying immersion periods at 303 K. FCS showed the highest value of $95.96 \%$ when the metal samples were immersed in 500 ppm concentration of inhibitor solution. Such good anticorrosion performance can be corroborated with enhanced adsorption of the heteroatoms of the inhibitor on the metal surface (Rugmini Ammal et al. 2018). Fig 4 (b) displays the variation in the corrosion inhibition efficiency of FCS with the change in temperature from 303 to $343 \mathrm{~K}$. The inhibition potential increases with temperature up to $313 \mathrm{~K}$ and after that is found to decrease slowly. Prolonged exposure of the metal surface to the inhibitor solution (> 6 hours) and an increase in temperature (> $313 \mathrm{~K})$ showed a slight decrease in the inhibition performance of FCS. The decreased stability of the adsorbed inhibitor on the longer exposure time and increased metal surface kinetic energy at higher temperatures may have led to the desorption process and hence a fall in efficiency (Fares et al. 2012b; Fathima et al. 2017).

Fig 4 Change in corrosion inhibition performance of FCS for mild steel in $1 \mathrm{M} \mathrm{HCl}$ at various (a) immersion periods (b) temperatures

The corrosion rate and the temperature can be related by the Arrhenius and transition state equations represented by the eq. 12 and eq. 13 .

$$
\begin{aligned}
& \log K_{C R}=\frac{-E_{a}}{2.303 R T}+\log A \text {-------------- eq. } 12 \\
& \log \frac{K_{C R}}{T}=\frac{R}{N h} \exp ^{\frac{\Delta S^{*}}{R}} \exp ^{\frac{-\Delta H^{*}}{R T}--------------~ e q . ~} 13
\end{aligned}
$$

where $\mathrm{E}_{\mathrm{a}}$ is the apparent activation energy, $\Delta \mathrm{S}^{*}$ and $\Delta \mathrm{H}^{*}$ refers to the entropy and enthalpy of activation. Table 1 lists the activation parameters calculated from the linear plots drawn based on eq. 12 and 13, namely log $\mathrm{K}_{\mathrm{CR}}$ vs. $1 / \mathrm{T}$ and $\log \left(\mathrm{K}_{\mathrm{CR} / \mathrm{T}}\right)$ vs. $1 / \mathrm{T}$. The $\mathrm{E}_{\mathrm{a}}$ values of the inhibited solutions are found to be less than that of the uninhibited solution. Such lower or unchanged Ea values can be corroborated with the chemical interaction between the metal and the heteroatoms of the FCS molecules (Larabi et al. 2005; Zhang et al. 2019a). The increased inhibition performance of FCS with the temperature rise implies that chemisorbed passive film formation is higher than the dissolution rate. The lowering values of the frequency factor A can be correlated with the decreased corrosion rate in the presence of FCS (Khadom et al. 2011). The positive values of $\Delta H^{*}$ reveals that the metal dissolution involves an endothermic process. The negative values of $\Delta \mathrm{S}^{*}$ declare the decrease in the disorderliness that may be due to the formation of the more orderly activation complex (A.Noor 2007).

Table 1 Activation parameters for mild steel in acid solution without and with FCS

The inhibition efficiency relies on the corrosion inhibitor's quickness to diffuse from the solution to the metal surface. Thereby, it replaces the adsorbed water molecules and effectively binds to the active sites present on the surface (Singh et al. 2019). The degree of surface coverage $\theta$ decides the nature and the mode of inhibitor adsorption (Arukalam et al. 2014). The $\theta$ values at different temperatures were calculated using eq. 14 and were fitted into various adsorption isotherm models. Based on the linear regression coefficient $\mathrm{R}^{2}$ values, Langmuir adsorption isotherm represented by eq. 15 was found to be the best fit.

$$
\begin{aligned}
& \text { Surface coverage } \theta=\frac{W b-W i}{W b}------------------e q .14 \\
& \frac{C}{\theta}=\frac{1}{K_{\text {ads }}}+C \text {-----------------------------------eq.15 }
\end{aligned}
$$


where $\mathrm{C}$ represents the inhibitor concentration, and $\mathrm{K}_{\mathrm{ads}}$ refers to the equilibrium constant. Fig 5 displays the Langmuir plot, and slope values are found to deviate from unity. The slope deviation reveals that in addition to $\mathrm{R}^{2}$ values, another physical characteristic $\mathrm{K}_{\mathrm{L}}$ of the adsorption isotherm is to be considered for the best fit (Eduok and Khaled 2015; Singh et al. 2018). $\mathrm{K}_{\mathrm{L}}$ is referred to as the dimensionless separation factor of inhibitor adsorption and is related to $\mathrm{K}_{\mathrm{ads}}$ by the following equation

$$
K_{L}=1 / 1+K_{a d s} C
$$

The average values of $\mathrm{K}_{\mathrm{L}}$ values calculated based on eq. 6 is displayed in Table 2. According to Eduok and Khaled, if $\mathrm{K}_{\mathrm{L}}<1$, then the adsorption process is considered favorable. If $\mathrm{K}_{\mathrm{L}}>1$ or $\mathrm{K}_{\mathrm{L}}=1$ then, the adsorption process is unfavorable or deemed to be irreversible (Eduok and Khaled 2015). Based on this literature, it is clear that the FCS inhibitor favors the Langmuir adsorption process.

. Fig 5 Langmuir isotherm plot for mild steel in $1 \mathrm{M} \mathrm{HCl}$ without and with FCS

Table 2 lists the other adsorption parameters calculated for mild steel in $1 \mathrm{M}$ hydrochloric acid without and with FCS inhibitor. The standard free energy of adsorption $\Delta$ Gads is calculated using the following equation:

$$
\Delta G_{a d s}=-\mathrm{RT} \ln \left(1 * 10^{6} \mathrm{~K}_{\text {ads }}\right) \text {--------------------eq.17 }
$$

where $\mathrm{R}$ represents the ideal gas constant, $\mathrm{T}$ is the temperature in Kelvin, and $10^{6}$ is the value of water concentration in ppm (Roy et al. 2014). The negative values of $\Delta \mathrm{G}_{\text {ads }}$ support the spontaneity of the adsorption process. When the values of $\Delta \mathrm{G}_{\mathrm{ads}}$ is less than $20 \mathrm{~kJ} / \mathrm{mole}$ corresponds to physisorption, and greater than 40 $\mathrm{kJ} / \mathrm{mole}$ conforms to chemisorption (Xu et al. 2017). The $\Delta \mathrm{G}_{\mathrm{ads}}$ values listed in Table 2 lies between 28 to $32 \mathrm{~kJ} /$ mol. These values can be corroborated with the initial electrostatic interaction between the FCS inhibitor and the metal surface, leading to physisorption. The transfer of electron pairs from the heteroatoms to the empty d orbitals of $\mathrm{Fe}^{2+}$ ions and retro donation to the unoccupied $\pi^{*}$ orbital of the FCS molecule occurs, resulting in the chemisorption process (Espinoza-Vázquez et al. 2019). The value of $\mathrm{K}_{\mathrm{ads}}$ also reflects the increased binding of the inhibitor molecules on the metal surface (Singh et al. 2018).

Table 2 Adsorption parameters for mild steel in $1 \mathrm{M} \mathrm{HCl}$ without and with FCS inhibitor at different temperatures

\subsubsection{Electrochemical measurement techniques}

\subsubsection{Polarization/ Tafel studies}

Tafel studies help to analyze the influence of the inhibitor to mitigate the corrosion process taking place at the anode or cathode or both. Fig 6 illustrates the polarization curves obtained for mild steel at room temperature in the absence and presence of FCS inhibitor. The Tafel plot depicts the decrease of current density with an increase in FCS concentration. The decrease implies that the inhibitor film formed impedes the passage of aggressive ions to the metal surface (Eduok and Khaled 2015). Table 3 display the various corrosion parameters obtained from the Tafel polarization curves. The $\mathrm{E}_{\text {corr }}$ values can be related to the driving force towards the

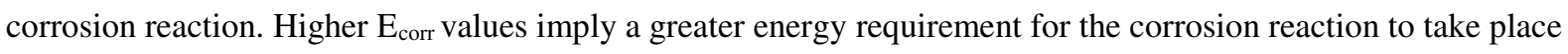
(Subramanian et al. 2015). The positive shift of $E_{\text {corr }}$ values from $-443 \mathrm{mV}$ to $-189 \mathrm{mV}$ illustrates the corrosion inhibition performance of the inhibitor (Al-Amiery et al. 2016). This potential shift is further supported by the lowering of the corrosion current $i_{\text {corr }}$ density (Erna et al. 2019). The change in both anodic $(\beta a)$ and cathodic Tafel slopes $(\beta c)$ reveals that the inhibitor influences both cathodic and anodic reactions but predominantly anodic (Alamiery et al. 2018) The LPR values increases with the concentration of the FCS polymer as displayed in Table 
2. This increase indicates a decreased metal dissolution due to the adsorption of the inhibitor molecules on the metal surface. The inhibition efficiency calculated using $i_{\text {corr }}$ values showed a maximum of $97.4 \%$ for $500 \mathrm{ppm}$ concentration which matches with those calculated from LPR values.

Fig 6 Tafel plot for mild steel in $1 \mathrm{M} \mathrm{HCl}$ with and without FCS

Table 3 Tafel electrochemical parameters for mild steel in $1 \mathrm{M} \mathrm{HCl}$ without and with FCS

\subsubsection{AC Electrochemical impedance studies}

EIS technique has emerged out as an excellent tool to study the effectiveness of the corrosion inhibitors, both qualitatively and quantitatively (Meeusen et al. 2019). Fig 7 (a) \& (b) represents the Nyquist and Bode cum phase angle plots obtained for mild steel in blank and in the presence of FCS. The Nyquist plot clearly shows an increase in the diameter of the impedance plot with the inhibitor concentration. This increase can be attributed to the inhibitor film formation by protecting the metal surface from corrosion (Kumar et al. 2016). The inhibition of corrosion is further supported by the rise in the phase angle with the increase in the inhibitor's concentration, as shown in the Bode plot (Yildiz 2015). The Bode plot reveals only one time constant, which can be corroborated with the corrosion inhibition by the charge transfer process and is not changed by the inhibitor's presence (Solmaz 2014). The semi-circle in the Nyquist plot is not perfect due to the metal surface's inhomogeneity, surface irregularities, impurities, surface active sites collectively referred as frequency dispersion effect (EspinozaVázquez et al. 2019)(Chakravarthy and Mohana 2014). Table 4 lists the equivalent circuit fitted impedance parameters, and Fig 8 displays the equivalent circuit. The double-layer capacitance $\mathrm{C}_{\mathrm{dl}}$ can be calculated from the $\mathrm{Y}_{0}$ values using the eq.18.

$$
C_{d l}=\left(Y_{0} * R_{c t}{ }^{1-n}\right)^{1 / n} \text {---------------eq.18 }
$$

The decreasing $\mathrm{C}_{\mathrm{dl}}$ values and increasing charge transfer resistance $\left(\mathrm{R}_{\mathrm{p}}\right)$ values with FCS concentration can be correlated with the increased thickness of the protective film leading to an increased corrosion inhibition (Xu et al. 2019).

Fig 7 (a) Nyquist plot (b) Bodes, phase angle plots for mild steel in $1 \mathrm{M} \mathrm{HCl}$ without and with FCS inhibitor at $303 \mathrm{~K}$

Fig 8 Equivalent circuit

Table 4 EIS parameters for mild steel in $1 \mathrm{M} \mathrm{HCl}$ without and with FCS

\subsection{Surface characterization}

\subsubsection{Contact angle measurements}

Fig 9 displays the contact angle of (a) plain metal surface, (b) \&(c) the metal surfaces exposed to acid and acid containing FCS, respectively. An angle of $90^{\circ}$ or less indicates that the steel surface is hydrophilic and higher than $90^{\circ}$ hydrophobic. The enhanced hydrophobic nature of the inhibitor immersed metal sample reveals the FCS's adsorption on the metal surface, leading to the protective film formation (Reddy et al. 2016)(Marijan Babic 2017).

Fig 9 Contact angle of mild steel surfaces (a) plain (b) exposed to acid (c) exposed to acid containing the FCS inhibitor

\subsubsection{Field emission scanning electron microscopic analysis}

Fig.10 (a) portrays the scanning electron microscopic images of the metal surface before exposure to the acid solution. Fig 10 (b) depicts the extensive damage produced when the metal sample is in contact with the 
aggressive acid medium in the inhibitor's absence. Fig 10 (c) reflects the resistance offered by the FCS inhibitor against the metal dissolution as the surface is smooth as that of the plain metal.

Fig 10 SEM image of the mild steel surfaces (a) plain (b) exposed to acid (c) exposed to acid containing FCS

\subsubsection{Energy dispersive $x$-ray analysis}

EDAX images with \% of different element contents of the bare metal surface, surface exposed to uninhibited and inhibited acid solution are displayed in Fig.11 (a-c). The $\mathrm{Cl}$ and $\mathrm{O}$ content on the metal surface exposed to acid can be corroborated with the formation of corrosion products such as chlorides and oxides on the metal surface. The decrease in the iron, $\mathrm{C}$, and $\mathrm{O}$ content indicates an organic film on the metal surface exposed to the inhibited acid solution (Hamdy and El-Gendy 2013).

Fig 11 EDAX image of surfaces (a) plain metal (b) exposed to $1 \mathrm{M} \mathrm{HCl}$ (c) exposed to $1 \mathrm{M} \mathrm{HCl}$ containing FCS

\subsubsection{Optical profilometric studies}

Fig 12 (a-c) portrays the optical profilometric images of the bare metal surface and surfaces exposed to uninhibited and inhibited solution. Arithmetic average roughness value $(\mathrm{Sa})$ and the root mean square roughness value (Sq) for the well-polished plain metal surface were found to be $1.551 \mu \mathrm{m}$ and $1.977 \mu \mathrm{m}$, respectively. The metal surface exposed to uninhibited acid solution showed an increased roughness value of $3.371 \mu \mathrm{m}$ (Sa) and $4.456 \mu \mathrm{m}(\mathrm{Sq})$. However, the metal surface exposed to an acid solution containing an optimum FCS concentration has shown a decreased surface roughness value of $1.597 \mu \mathrm{m}$ (Sa) and $2.305 \mu \mathrm{m}(\mathrm{Sq})$. This decrease may be corroborated with the reduction in corrosion in the presence of the inhibitor (Sliem et al. 2019).

Fig 12 3D images of mild steel surfaces (a) Plain metal (b) exposed to acid and (c) exposed to acid containing FCS

\subsubsection{Atomic force microscopy (AFM)}

AFM is a useful tool for monitoring the corrosion processes by visualizing the surface morphology of different materials. Fig.13 (a-c) and Fig. 14 (a-c) represent 2 D and 3 D AFM images of the bare metal surface, metal surface exposed to uninhibited and inhibited solution, for 6 hours. It is evident from Table 5 that the average roughness value and root mean square value of the metal sample exposed to acid containing FCS shows a significant decrease. This result can be corroborated with the film formed by the inhibitor adsorbed on the metal surface (Shainy et al. 2016).

Fig $13 \mathrm{AFM}(2 \mathrm{D}$ ) image of surfaces (a) plain metal (b) exposed to $1 \mathrm{M} \mathrm{HCl}$ and (c) exposed to $1 \mathrm{M} \mathrm{HCl}$ containing FCS

Fig $14 \mathrm{AFM} \mathrm{(3} \mathrm{D)} \mathrm{images} \mathrm{of} \mathrm{surfaces} \mathrm{(a)} \mathrm{plain} \mathrm{metal} \mathrm{(b)} \mathrm{exposed} \mathrm{to} 1 \mathrm{M} \mathrm{HCl}$ and (c) exposed to $1 \mathrm{M} \mathrm{HCl}$ containing FCS

Table 5 AFM parameters for mild steel surface exposed to acid without and with FCS

\subsubsection{UV spectral analysis}

Fig 15 depicts the UV-visible spectra of FCS solution before and after the immersion of mild steel samples. The UV-vis spectrum of FCS solution before immersion of the metal samples show absorption bands at $290 \mathrm{~nm}$ and $321 \mathrm{~nm}$. These bands correspond to the $\pi-\pi^{*}$ electronic transitions of the aromatic ring and $\mathrm{n}-\pi^{*}$ transitions by the lone pair of electrons on the nitrogen and carbonyl group, respectively (Abboud et al. 2007). On the other hand, the UV-vis spectrum of the FCS solution taken after 6 hours of immersion of metal samples shows an increase in the absorbance bands from $321 \mathrm{~nm}$ to $266 \mathrm{~nm}$ (blue shift). Besides, the absorbance band at $290 \mathrm{~nm}$ 

interactions of the heteroatoms of the FCS inhibitor and the $\mathrm{Fe}^{2+}$ ions resulting in the complex formation (AbdelGaber et al. 2006; Meng et al. 2017; Aloysius et al. 2018).

Fig 15 UV-visible spectra of FCS solution before and after introducing the mild steel samples 4 Theoretical studies

\subsection{DFT studies}

DFT studies serve as a successful tool in predicting the reciprocity between the inhibitor and the metal. The theory throws light on the chemical reactivity and selectivity of corrosion inhibitors, thereby aid to propose a suitable mechanism for the corrosion inhibition process. The quantum chemical calculations were performed for the neutral FCS molecule and also for the protonated form as the study is done in an acid medium. These calculations will enable identifying the preferred form of the inhibitor that can selectively interact with the metal surface.

Fig.16 displays the optimized geometry, frontier molecular orbitals, electrostatic potential mapping of the FCS in both forms. The nitrogen atom in the optimized structure of the neutral FCS possesses the highest Mulliken value (-0.4578) and therefore was chosen as the site for protonation. The electron density distribution plots of the frontier molecular orbitals, i.e., HOMO and LUMO orbitals, are useful to locate the preferred sites of adsorption in the inhibitor molecules. The electron distribution is solely on the ferulic acid moiety and the methyl group of the methoxy group of the ferulic acid moiety is found to contribute to a smaller extent to the HOMO and no contribution to the LUMO; in both neutral and protonated forms. This suggests the charge transfer by the - $\mathrm{CH}_{3}$ group of ferulic acid through $\mathrm{s}$ - type HOMO and the heteroatoms of the chitosan moiety to the vacant orbital d orbital of the Fe on the mild steel surface (Zhang et al. 2019b). The electrostatic potential structure reveals the nucleophilic region (red color) and the electrophilic region (blue) of the FCS inhibitor (Xu et al. 2018).

Table 6 gives quantum chemical parameters calculated based on the density functional theory for the neutral and protonated FCS molecule. The $\mathrm{E}_{\text {номо }}$ and $\mathrm{E}_{\mathrm{Lumo}}$ values provide valuable information regarding the electron donating and accepting capacity of the neutral and protonated FCS molecule. The greater the value of $\mathrm{E}_{\text {Hомо }}$, the more it behaves as an electron donor, and the lower $\mathrm{E}_{\mathrm{LUMO}}$ value characterizes electron acceptors. When an inhibitor shows a tendency to donate electrons to the metal surface and at the same time tends to accept the electrons back donated by the metal, then stronger is the adsorption process (Fouda et al. 2017; Chauhan et al. 2018b). Table 6 reveals that neutral and protonated molecules behave as an electron donor and a good electron acceptor, respectively. This behavior can be corroborated with the increased global electronegativity $(\chi)$, electrophilicity index $(\omega)$ values of the protonated FCS molecule, and the higher fraction of the electron transfer $(\Delta \mathrm{N})$ value for the neutral molecule (Chauhan et al. 2018b). Electrophilicity index value denotes the energy stabilization after accepting the additional electrons from the environment. The energy gap $(\Delta \mathrm{E})$ between the frontier molecular orbitals measures the kinetic stability of the corrosion inhibitor (Gece 2015). Smaller energy gap values indicate lesser kinetic stability and hence greater reactivity with the metal surface. Thus, protonated form contributes to the better performance of the inhibitor than that of the neutral molecule. Dipole moment $(\mu)$ values can be related to the electrostatic interaction between the inhibitor molecules and the metal surface. The higher values of the dipole moment reveal that protonated molecule contributes physisorption process compared 
Fig 16 Optimized molecular structure, frontier MO and electrostatic potential mapping of neutral and protonated FCS

Table 6 Quantum chemical parameters of neutral and protonated FCS molecule

\subsection{Monte Carlo and Molecular Dynamic simulation studies}

The interaction of the FCS and FCS-H+ onto the Fe (110) surface offers a mean to calculate the adsorption energetics of this adsorption process. Quantitatively, this is done by calculating the adsorption energy (Eads) using the following equation (Mehmeti and Berisha 2017; Dagdag et al. 2019b, 2020c; Hsissou et al. 2019a, 2020a; El Arrouji et al. 2020; Rbaa et al. 2020b, a; Thaçi et al. 2020; Jessima et al. 2020a):

$$
E_{\text {adsorption }}=E_{\mathrm{Fe}(110) \| \mathrm{FCS} \text { or } \mathrm{FCS}-\mathrm{H}+}-\left(E_{\mathrm{Fe}(110)}+E_{\mathrm{FCS} \text { or } \mathrm{FCS}-\mathrm{H}+}\right) \text {-------------eq.19 }
$$

where $E_{\mathrm{Fe}(110)_{||} \mathrm{FCS} \text { or FCS-H+ }}$ is the total energy of the simulated corrosion system, $\mathrm{E}_{\mathrm{Fe}}$, and $\mathrm{E}$ FCS or FCS $-\mathrm{H}+$ are the total energy values of the $\mathrm{Fe}(110)$ surface and the free inhibitor molecules (in their neutral or protonated state) (Jessima et al. 2020a).

The lowest energy configuration of FCS and FCS-H+ on the Fe (110) surface is presented in Fig 17. The inhibitor is absorbed on the $\mathrm{Fe}(110)$ surface in a geometry that takes advantage of the surface contact through its oxygen atoms.

The energy values (in terms of different contributions) over the random MC configuration search are shown in Fig 18. After 3000000 MC steps as perceived from the graph, the value of total average energy is equilibrated, indicating that the lowest energy configuration of the inhibitors was attained.

The Eads. distribution of the FCS and FCS-H+ inhibitor gained by a massive number of unsystematic configurations from Monte Carlo calculations (values of adsorption energies for ten lowest energy poses are presented in supporting information Table S1) is presented in Fig 19.

Fig 17 MC poses the lowest adsorption configurations for the FCS and FCS-H+ in the simulated corrosion media on the Fe (1 110$)$ surface

Fig 18 The presentation of the different energy terms contributions during the Monte Carlo calculations for FCS (neutral) and FCS-H+ (protonated) inhibitor molecule

Fig 19 Distribution of adsorption energies for: FCS (neutral) and FCS-H+ (protonated) inhibitor onto the $\mathrm{Fe}(110)$ surface

The $\mathrm{E}_{\text {ads }}$ onto Fe surface values (Fig 17) for the FCS adsorption is from -239.35 to $-285.55 \mathrm{kcal} / \mathrm{mol}$ (with the maximum value of Eads probability distribution at $-262.15 \mathrm{kcal} / \mathrm{mol}$ ). The adsorption energies are higher for the protonated form of the FCS molecule (namely FCS-H+). They are in the range of -372.95 to -415.86 $\mathrm{kcal} / \mathrm{mol}$ (with the maximum value of Eads probability distribution at $-395.85 \mathrm{kcal} / \mathrm{mol}$ ). These huge Eads. are suggestive of a strong adsorptive interaction of this inhibitor with the Fe (110) surface (Hsissou et al. 2019a, c; Dagdag et al. 2020d) 

only covers a small fraction of the iron surface. In the case of the protonated FCS it's adsorption properties increase - in this case, the molecule tends to have a flat geometry onto the Fe $\left(\begin{array}{lll}1 & 1 & 0\end{array}\right)$ surface (the equilibration of the temperature and the energy terms during the MD simulations are shown in the supporting information).

Fig 20 MD poses the lowest adsorption configurations for the FCS and FCS-H+ in the simulated corrosion media on the Fe (lllll 110$)$ surface

Fig 21 RDF of heteroatoms (nitrogen and oxygen,) for FCS and FCS-H+ on the Fe surface obtained from MD trajectory

A modest method to attain the information vis-à-vis the adsorption process is to use the RDF peak appearance distance (Berisha 2020; Dagdag et al. 2020d, e; El Arrouji et al. 2020; Rbaa et al. 2020b). The peak presence for the FCS and FCS-H+ inhibitor is at a lesser distance than $3.5 \AA$ from the surface of Fe indicates the chemisorption process, while for physisorption, this is projected at larger distances. As evidenced in Fig 21, the RDF value for nitrogen and oxygen atoms in the FCS-H+ case is present at $3.01 \AA(\mathrm{O})$ and $3.07 \AA(\mathrm{N})$ from the $\mathrm{Fe}$ (110) surface - an expected value for the chemisorption process. Whereas for the FCS, accountable atoms for the absorption are oxygen atoms $[R D F$ is $2.97 \AA(\mathrm{O})]$; the nitrogen atoms, as evidenced from the RDF distance of $8.80 \AA(\mathrm{N})$ are do not contribute to the adsorption process. The corresponding RDF analysis support that the chemisorption is involved during the adsorption of the inhibitor that decreases the corrosion rate of the Fe (110) surface (Dagdag et al. 2019b, 2020c; Hsissou et al. 2019c, 2020b, c; Abbout et al. 2020).

\section{Conclusion}

- The corrosion inhibition performance of FCS reached $95.96 \%$ at 500 ppm and 6 hours of immersion period.

- The present investigation reveals a chemical interaction between the $\mathrm{Fe}^{2+}$ ions on the metal surface and the heteroatoms of the FCS molecules during the adsorption process.

- Tafel studies showed that the FCS inhibitor was a mixed type inhibiting both the cathodic hydrogen evolution and anodic dissolution of the mild steel metal.

- Protonated molecule contributes to the inhibitor efficiency more than that of the neutral molecule.

- FCS shows that it is an efficient, green corrosion inhibitor that can be used as an additive during acid cleaning of mild steel.

- $\quad \mathrm{MC}$ and MD calculations validate that there is a vigorous adsorptive interaction that takes place amongst the FCS inhibitor (in the neutral and protonated state) and the Fe surface. The obtained theoretical results are in good agreement with the experimental results.

\section{Declarations}

The authors declare that they have no known competing financial interests or personal relationships that could have appeared to influence the work reported in this paper.

Declarations of interest: None

\section{Compliance with Ethical Standards}

Conflict of Interest: On behalf of all authors, the corresponding author states that there is no conflict of interest. 
S J Hepziba Magie Jessima: Conceptualization, Methodology, Writing- Original draft preparation. Avni Berisha and Valbonë Mehmeti: Writing, computational software Monte Carlo simulation studies, Subramanian Sathy Srikandan: Electrochemical studies S. Subhashini: Supervision., Reviewing and Editing,

\section{Acknowledgments}

The authors would like to thank Indian Institute of Science, Bangalore, India for doing the computational analysis. Avni Berisha gratefully acknowledges the support from the Ministry of Education, Science and Technology of Kosovo (Nr.2-5069) for providing the computing resources.

\section{References}

A.Noor E (2007) Temperature Effects on the Corrosion Inhibition of Mild Steel in Acidic Solutions by Aqueous Extract of Fenugreek Leaves. Int J Electrochem Sci 2:996-1017

Abboud Y, Abourriche A, Saffaj T, et al (2007) 2,3-Quinoxalinedione as a novel corrosion inhibitor for mild steel in $1 \mathrm{M} \mathrm{HCl}$. Mater Chem Phys 105:1-5. https://doi.org/10.1016/j.matchemphys.2007.03.037

Abbout S, Zouarhi M, Chebabe D, et al (2020) Galactomannan as a new bio-sourced corrosion inhibitor for iron in acidic media. Heliyon 6:. https://doi.org/10.1016/j.heliyon.2020.e03574

Abdel-Gaber AM, Abd-El-Nabey BA, Sidahmed IM, et al (2006) Inhibitive action of some plant extracts on the corrosion of steel in acidic media. Corros Sci 48:2765-2779. https://doi.org/10.1016/j.corsci.2005.09.017

Al-Amiery AA, Binti Kassim FA, Kadhum AAH, Mohamad AB (2016) Synthesis and characterization of a novel eco-friendly corrosion inhibition for mild steel in $1 \mathrm{M}$ hydrochloric acid. Sci Rep 6:1-13. https://doi.org/10.1038/srep19890

Al-amiery AA, Othman MH, Adnan T, et al (2018) Results in Physics Electrochemical studies of novel corrosion inhibitor for mild steel in $1 \mathrm{M}$ hydrochloric acid. Results Phys 9:978-981. https://doi.org/10.1016/j.rinp.2018.04.004

Almeida RR, Silva Damasceno ET, de Carvalho SYB, et al (2018) Chitosan nanogels condensed to ferulic acid for the essential oil of Lippia origanoides Kunth encapsulation. Carbohydr Polym 188:268-275. https://doi.org/10.1016/j.carbpol.2018.01.103

Aloysius A, Ramanathan R, Christy A, et al (2018) Experimental and theoretical studies on the corrosion inhibition of vitamins - Thiamine hydrochloride or biotin in corrosion of mild steel in aqueous chloride environment. Egypt J Pet 27:371-381. https://doi.org/10.1016/j.ejpe.2017.06.003

Arukalam IO, Madu IO, Ijomah NT, et al (2014) Acid Corrosion Inhibition and Adsorption Behaviour of Ethyl Hydroxyethyl Cellulose on Mild Steel Corrosion. J Mater 2014:1-11. https://doi.org/10.1155/2014/101709

Berisha A (2019) The influence of the grafted aryl groups on the solvation properties of the graphyne and graphdiyne- A MD study. Open Chem 17:703-710. https://doi.org/10.1515/chem-2019-0083 
Berisha A (2020) Experimental, Monte Carlo and Molecular Dynamic Study on Corrosion Inhibition of Mild Steel by Pyridine Derivatives in Aqueous Perchloric Acid. Electrochem 1:188-199. https://doi.org/10.3390/electrochem1020013

Boujakhrout A, Hamdani I, Chahboun N, et al (2015) Antioxidant activity and corrosion inhibitive behavior of Garcinia cola seeds on mild steel in hydrochloric medium. J Mater Environ Sci 6:3655-3666

Brou YS, Coulibaly NH, Diki NGYS, et al (2020) Chitosan biopolymer effect on copper corrosion in 3.5 wt.\% NaCL solution: Electrochemical and quantum chemical studies. Int J Corros Scale Inhib 9:182-200. https://doi.org/10.17675/2305-6894-2020-9-1-11

Chakravarthy MP, Mohana KN (2014) Adsorption and corrosion inhibition characteristics of some nicotinamide derivatives on mild steel in hydrochloric acid solution. ISRN Corros 2014:1-13. https://doi.org/10.1155/2014/687276

Charitha BP, Rao P (2017) Starch as an ecofriendly green inhibitor for corrosion control of 6061-Al alloy. J Mater Environ Sci 8:78-89

Chatterjee NS, Anandan R, Navitha M, et al (2016) Development of thiamine and pyridoxine loaded ferulic acid-grafted chitosan microspheres for dietary supplementation. 53:551-560. https://doi.org/10.1007/s13197-015-2044-4

Chauhan DS, Ansari KR, Sorour AA, et al (2018a) Thiosemicarbazide and thiocarbohydrazide functionalized chitosan as ecofriendly corrosion inhibitors for carbon steel in hydrochloric acid solution. Int J Biol Macromol 107:1747-1757. https://doi.org/10.1016/j.ijbiomac.2017.10.050

Chauhan DS, Srivastava V, Joshi PG, Quraishi MA (2018b) PEG cross-linked Chitosan: a biomacromolecule as corrosion inhibitor for sugar industry. Int J Ind Chem 9:363-377. https://doi.org/10.1007/s40090-0180165-0

Dagdag O, Berisha A, Safi Z, et al (2020a) DGEBA-polyaminoamide as effective anti-corrosive material for 15CDV6 steel in NaCl medium: Computational and experimental studies. J Appl Polym Sci 137:48402. https://doi.org/10.1002/app.48402

Dagdag O, Berisha A, Safi Z, et al (2020b) Highly durable macromolecular epoxy resin as anticorrosive coating material for carbon steel in 3\% NaCl: Computational supported experimental studies. J Appl Polym Sci. https://doi.org/10.1002/app.49003

Dagdag O, Berisha A, Safi Z, et al (2020c) DGEBA-polyaminoamide as effective anti-corrosive material for 15CDV6 steel in $\mathrm{NaCl}$ medium: Computational and experimental studies. J Appl Polym Sci 137:1-10. https://doi.org/10.1002/app.48402

Dagdag O, El Harfi A, El Gouri M, et al (2019a) Anticorrosive properties of Hexa (3-methoxy propan-1,2-diol) cyclotri-phosphazene compound for carbon steel in $3 \% \mathrm{NaCl}$ medium: gravimetric, electrochemical, DFT and Monte Carlo simulation studies. Heliyon 5:. https://doi.org/10.1016/j.heliyon.2019.e01340

Dagdag O, Hsissou R, Berisha A, et al (2019b) Polymeric-Based Epoxy Cured with a Polyaminoamide as an 
Dagdag O, Hsissou R, El Harfi A, et al (2020d) Fabrication of polymer based epoxy resin as effective anticorrosive coating for steel: Computational modeling reinforced experimental studies. Surfaces and Interfaces 18:. https://doi.org/10.1016/j.surfin.2020.100454

Dagdag O, Hsissou R, El Harfi A, et al (2020e) Epoxy resins and their zinc composites as novel anti-corrosive materials for copper in 3\% sodium chloride solution: Experimental and computational studies. J Mol Liq 315:113757. https://doi.org/10.1016/j.molliq.2020.113757

Eduok UM, Khaled M (2015) Corrosion inhibition for low-carbon steel in 1 M H2SO4 solution by phenytoin: evaluation of the inhibition potency of another "anticorrosive drug." Res Chem Intermed 41:6309-6324. https://doi.org/10.1007/s11164-014-1741-3

El-Haddad MN (2013) Chitosan as a green inhibitor for copper corrosion in acidic medium. Int J Biol Macromol 55:142-149. https://doi.org/10.1016/j.ijbiomac.2012.12.044

El Arrouji S, Karrouchi K, Berisha A, et al (2020) New pyrazole derivatives as effective corrosion inhibitors on steel-electrolyte interface in $1 \mathrm{M} \mathrm{HCl}$ : Electrochemical, surface morphological (SEM) and computational analysis. Colloids Surfaces A Physicochem Eng Asp 604:. https://doi.org/10.1016/j.colsurfa.2020.125325

Elbasuney S, Gobara M, Zoriany M, et al (2019) The significant role of stabilized colloidal ZrO2 nanoparticles for corrosion protection of AA2024. Environ Nanotechnology, Monit Manag 12:. https://doi.org/10.1016/j.enmm.2019.100242

Erna M, Herdini H, Futra D (2019) Corrosion Inhibition Mechanism of Mild Steel by AmyloseAcetate/Carboxymethyl Chitosan Composites in Acidic Media. Int J Chem Eng 2019:. https://doi.org/10.1155/2019/8514132

Espinoza-Vázquez A, Rodríguez-Gómez FJ, Martínez-Cruz IK, et al (2019) Adsorption and corrosion inhibition behaviour of new theophylline-triazole-based derivatives for steel in acidic medium. R Soc Open Sci 6:. https://doi.org/10.1098/rsos.181738

Fares MM, Maayta AK, Al-Mustafa JA (2012a) Corrosion inhibition of iota-carrageenan natural polymer on aluminum in presence of zwitterion mediator in $\mathrm{HCl}$ media. Corros Sci 65:223-230. https://doi.org/10.1016/j.corsci.2012.08.018

Fares MM, Maayta AK, Al-Qudah MM (2012b) Pectin as promising green corrosion inhibitor of aluminum in hydrochloric acid solution. Corros Sci 60:112-117. https://doi.org/10.1016/j.corsci.2012.04.002

Fathima A, Abdul S, Sethumanickam S (2017) Corrosion inhibition, adsorption and thermodynamic properties of poly ( vinyl alcohol- cysteine ) in molar HCl. Arab J Chem 10:S3358-S3366. https://doi.org/10.1016/j.arabjc.2014.01.016

Faydy M El, Benhiba F, Berisha A, et al (2020) An experimental-coupled empirical investigation on the corrosion inhibitory action of 7-alkyl-8-Hydroxyquinolines on C35E steel in $\mathrm{HCl}$ electrolyte. J Mol Liq 
Finšgar M, Jackson J (2014) Application of corrosion inhibitors for steels in acidic media for the oil and gas industry: A review. Corros Sci 86:17-41. https://doi.org/10.1016/j.corsci.2014.04.044

Fiori-Bimbi M V., Alvarez PE, Vaca H, Gervasi CA (2015) Corrosion inhibition of mild steel in HCL solution by pectin. Corros Sci 92:192-199. https://doi.org/10.1016/j.corsci.2014.12.002

Fouda AS, Ismail MA, Abousalem AS, Elewady GY (2017) Experimental and theoretical studies on corrosion inhibition of 4-amidinophenyl-2,2'-bifuran and its analogues in acidic media. RSC Adv 7:46414-46430. https://doi.org/10.1039/c7ra08092a

Gece G (2015) Corrosion inhibition behavior of two quinoline chalcones: Insights from density functional theory. Corros Rev 33:195-202. https://doi.org/10.1515/corrrev-2015-0028

Giuliani C, Pascucci M, Riccucci C, et al (2018) Chitosan-based coatings for corrosion protection of copperbased alloys: A promising more sustainable approach for cultural heritage applications. Prog Org Coatings 122:138-146. https://doi.org/10.1016/j.porgcoat.2018.05.002

Gupta NK, Joshi PG, Srivastava V, Quraishi MA (2018) Chitosan: A macromolecule as green corrosion inhibitor for mild steel in sulfamic acid useful for sugar industry. Int J Biol Macromol 106:704-711. https://doi.org/10.1016/j.ijbiomac.2017.08.064

Hamdy A, El-Gendy NS (2013) Thermodynamic, adsorption and electrochemical studies for corrosion inhibition of carbon steel by henna extract in acid medium. Egypt J Pet 22:17-25. https://doi.org/10.1016/j.ejpe.2012.06.002

Hsissou R, Abbout S, Berisha A, et al (2019a) Experimental, DFT and molecular dynamics simulation on the inhibition performance of the DGDCBA epoxy polymer against the corrosion of the E24 carbon steel in 1.0 M HCl solution. J Mol Struct 1182:340-351. https://doi.org/10.1016/j.molstruc.2018.12.030

Hsissou R, Abbout S, Seghiri R, et al (2020a) Evaluation of corrosion inhibition performance of phosphorus polymer for carbon steel in [1 M] HCl: Computational studies (DFT, MC and MD simulations). J Mater Res Technol. https://doi.org/10.1016/j.jmrt.2020.01.002

Hsissou R, Benhiba F, Abbout S, et al (2020b) Trifunctional epoxy polymer as corrosion inhibition material for carbon steel in $1.0 \mathrm{M} \mathrm{HCl}$ : MD simulations, DFT and complexation computations. Inorg Chem Commun 115:107858. https://doi.org/10.1016/j.inoche.2020.107858

Hsissou R, Benzidia B, Rehioui M, et al (2020c) Anticorrosive property of hexafunctional epoxy polymer HGTMDAE for E24 carbon steel corrosion in 1.0 M HCl: gravimetric, electrochemical, surface morphology and molecular dynamic simulations. Polym Bull 77:3577-3601. https://doi.org/10.1007/s00289-019-02934-5

Hsissou R, Dagdag O, Abbout S, et al (2019b) Novel derivative epoxy resin TGETET as a corrosion inhibition of E24 carbon steel in $1.0 \mathrm{M} \mathrm{HCl}$ solution. Experimental and computational (DFT and MD simulations) methods. J Mol Liq 284:182-192. https://doi.org/10.1016/j.molliq.2019.03.180 
Hsissou R, Dagdag O, Abbout S, et al (2019c) Novel derivative epoxy resin TGETET as a corrosion inhibition of E24 carbon steel in $1.0 \mathrm{M} \mathrm{HCl}$ solution. Experimental and computational (DFT and MD simulations) methods. J Mol Liq 284:182-192. https://doi.org/10.1016/j.molliq.2019.03.180

Huffer et al Anticorrosion pigments with positive zeta potential

Hussin MH, Shah AM, Rahim AA, et al (2015) Antioxidant and anticorrosive properties of oil palm frond lignins extracted with different techniques. Ann For Sci 72:17-26. https://doi.org/10.1007/s13595-0140405-1

Jafar Mazumder MA (2019) Synthesis, characterization and electrochemical analysis of cysteine modified polymers for corrosion inhibition of mild steel in aqueous $1 \mathrm{M} \mathrm{HCl}$. RSC Adv 9:4277-4294. https://doi.org/10.1039/c8ra09833f

Jessima SJHM, Berisha A, Srikandan SS, Subhashini S (2020a) Preparation, characterization, and evaluation of corrosion inhibition efficiency of sodium lauryl sulfate modified chitosan for mild steel in the acid pickling process. J Mol Liq 114382. https://doi.org/10.1016/j.molliq.2020.114382

Jessima SJHM, Subhashini S, Arulraj J (2020b) Sunova spirulina Powder as an Effective Environmentally Friendly Corrosion Inhibitor for Mild Steel in Acid Medium. J Bio- Tribo-Corrosion 6:. https://doi.org/10.1007/s40735-020-00370-x

Jmiai A, El Ibrahimi B, Tara A, et al (2018) Alginate biopolymer as green corrosion inhibitor for copper in $1 \mathrm{M}$ hydrochloric acid: Experimental and theoretical approaches. J Mol Struct 1157:408-417. https://doi.org/10.1016/j.molstruc.2017.12.060

Júnior JMF, de Vasconcelos Silva MG, Monteiro JA, et al (2016) Evaluation of antioxidant activity and inhibition of corrosion by brazilian plant extracts and constituents. Int J Electrochem Sci 11:3862-3875. https://doi.org/10.20964/110388

Kartsonakis IA, Stamatogianni P, Karaxi EK, Charitidis CA (2020) Comparative study on the corrosion inhibitive effect of 2-mecraptobenzothiazole and Na2HPO4 on industrial conveying API 5L X42 pipeline steel. Appl Sci 10:. https://doi.org/10.3390/app10010290

Khadom AA, Yaro AS, Studies WL (2011) Protection of Low Carbon Steel in Phosphoric Acid by Potassium Iodide 1. 47:662-669. https://doi.org/10.1134/S2070205111050078

Khairou KS, Alfi AA, Mabrouk EM (2007) Natural polymers as corrosion inhibitors for aluminium and tin in acidic media. Mater Sci Res India 4:279-290. https://doi.org/10.13005/msri/040207

Kong P, Feng H, Chen N, et al (2019) Polyaniline/chitosan as a corrosion inhibitor for mild steel in acidic medium. RSC Adv 9:9211-9217. https://doi.org/10.1039/c9ra00029a

Kumar MNVR (2000) A review of chitin and chitosan applications. A Rev chitin chitosan Appl 46:1-27

Kumar S, Vashisht H, Olasunkanmi LO, et al (2016) Experimental and theoretical studies on inhibition of mild steel corrosion by some synthesized polyurethane tri-block co-polymers. Sci Rep 6:1-18. 
https://doi.org/10.1038/srep30937

Larabi L, Harek Y, Benali O, Ghalem S (2005) Hydrazide derivatives as corrosion inhibitors for mild steel in 1 M HCl. 54:256-262. https://doi.org/10.1016/j.porgcoat.2005.06.015

Li C, Li J Bin (2017) Preparation of chitosan-ferulic acid conjugate: Structure characterization and in the application of pharmaceuticals. Int J Biol Macromol 105:1539-1543. https://doi.org/10.1016/j.ijbiomac.2017.04.103

Li MM, Xu QJ, Han J, et al (2015) Inhibition action and adsorption behavior of green inhibitor Sodium carboxymethyl cellulose on copper. Int J Electrochem Sci 10:9028-9041

Liu J, Pu H, Liu S, et al (2017) Synthesis, characterization, bioactivity and potential application of phenolic acid grafted chitosan: A review. Carbohydr Polym. https://doi.org/10.1016/j.carbpol.2017.07.014

Liu J, Wen X yuan, Lu J feng, et al (2014) Free radical mediated grafting of chitosan with caffeic and ferulic acids: Structures and antioxidant activity. Int J Biol Macromol 65:97-106. https://doi.org/10.1016/j.ijbiomac.2014.01.021

Malekmohammadi Nouri P, Attar MM (2015) Experimental and quantum chemical studies on corrosion inhibition performance of fluconazole in hydrochloric acid solution. Bull Mater Sci 38:499-509. https://doi.org/10.1007/s12034-015-0865-4

Marijan Babic (2017) Role of Interfacial Chemistry on Wettability and Carbon Dioxide Corrosion of Mild Steels

Meeusen M, Zardet L, Homborg AM, et al (2019) A complementary electrochemical approach for time-resolved evaluation of corrosion inhibitor performance. J Electrochem Soc 166:C3220-C3232. https://doi.org/10.1149/2.0271911jes

Mehmeti V V., Berisha AR (2017) Corrosion study of mild steel in aqueous sulfuric acid solution using 4methyl-4h-1,2,4-triazole-3-thiol and 2-mercaptonicotinic acid-an experimental and theoretical study. Front Chem AUG:1-12. https://doi.org/10.3389/fchem.2017.00061

Menaka R, Subhashini S (2016) Chitosan Schiff base as eco-friendly inhibitor for mild steel corrosion in $1 \mathrm{M}$ HCl. J Adhes Sci Technol 30:1622-1640. https://doi.org/10.1080/01694243.2016.1156382

Meng Y, Ning W, Xu B, et al (2017) Inhibition of mild steel corrosion in hydrochloric acid using two novel pyridine Schiff base derivatives: A comparative study of experimental and theoretical results. RSC Adv 7:43014-43029. https://doi.org/10.1039/c7ra08170g

Mobin M, Rizvi M, Olasunkanmi LO, Ebenso EE (2017) Biopolymer from Tragacanth Gum as a Green Corrosion Inhibitor for Carbon Steel in $1 \mathrm{M} \mathrm{HCl} \mathrm{Solution.} \mathrm{ACS} \mathrm{Omega} \mathrm{2:3997-4008.}$ https://doi.org/10.1021/acsomega.7b00436

Mohamed RR, Fekry AM (2011) Antimicrobial and anticorrosive activity of adsorbents based on chitosan schiff’s base. Int J Electrochem Sci 6:2488-2508 
Momin MIK, Bahadur I, Ebenso EE, et al (2016) Antioxidant properties, computational studies and corrosion inhibition potential of 3-hydroxy-1-(2-hydroxyphenyl)-5-(phenyl)-2,4-pentadien-1-one analogues. J Mol Liq 223:819-827. https://doi.org/10.1016/j.molliq.2016.08.107

Obot IB, Onyeachu IB, Kumar AM (2017) Sodium alginate: A promising biopolymer for corrosion protection of API X60 high strength carbon steel in saline medium. Carbohydr Polym 178:200-208. https://doi.org/10.1016/j.carbpol.2017.09.049

Parveen M, Mobin M, Zehra S, Aslam R (2018) L-proline mixed with sodium benzoate as sustainable inhibitor for mild steel corrosion in $1 \mathrm{M} \mathrm{HCl}$ : An experimental and theoretical approach. Sci Rep 8:1-18. https://doi.org/10.1038/s41598-018-24143-2

Peter A, Obot IB, Sharma SK (2015) Use of natural gums as green corrosion inhibitors: an overview. Int J Ind Chem 6:153-164. https://doi.org/10.1007/s40090-015-0040-1

Prabakaran M, Hemapriya V, Kim SH, Chung IM (2019) Evaluation of Antioxidant and Anticorrosion Properties of Epipremnum aureum. Arab J Sci Eng 44:169-178. https://doi.org/10.1007/s13369-0183398-5

Queiroz MF, Melo KRT, Sabry DA, et al (2015) Does the use of chitosan contribute to oxalate kidney stone formation? Mar Drugs 13:141-158. https://doi.org/10.3390/md13010141

Rahman MM, Zahir H, Haq B, Shehri DA Al (2018) Corrosion Inhibition Properties of Waterborne poly urethane/cerium nitrate coatings on mild steel. Coatings. https://doi.org/10.3390/coatings8010034

Rbaa M, Dohare P, Berisha A, et al (2020a) New Epoxy sugar based glucose derivatives as eco friendly corrosion inhibitors for the carbon steel in $1.0 \mathrm{M} \mathrm{HCl}$ : Experimental and theoretical investigations. J Alloys Compd 833:154949. https://doi.org/10.1016/j.jallcom.2020.154949

Rbaa M, Ouakki M, Galai M, et al (2020b) Simple preparation and characterization of novel 8Hydroxyquinoline derivatives as effective acid corrosion inhibitor for mild steel: Experimental and theoretical studies. Colloids Surfaces A Physicochem Eng Asp 602:125094. https://doi.org/10.1016/j.colsurfa.2020.125094

Reddy CM, Sanketi BD, Narendra Kumar S (2016) Corrosion inhibition of mild steel by Capsicum annuum fruit paste. Perspect Sci 8:603-605. https://doi.org/10.1016/j.pisc.2016.06.033

Roy P, Karfa P, Adhikari U, Sukul D (2014) Corrosion inhibition of mild steel in acidic medium by polyacrylamide grafted Guar gum with various grafting percentage : Effect of intramolecular synergism. Corros Sci. https://doi.org/10.1016/j.corsci.2014.07.039

Rugmini Ammal P, Prajila M, Joseph A (2018) Effective inhibition of mild steel corrosion in hydrochloric acid using EBIMOT, a 1, 3, 4-oxadiazole derivative bearing a 2-ethylbenzimidazole moiety: Electro analytical, computational and kinetic studies. Egypt J Pet 27:823-833. https://doi.org/10.1016/j.ejpe.2017.12.004

Sangeetha Y, Meenakshi S, Sairam Sundaram C (2016) Corrosion inhibition of aminated hydroxyl ethyl cellulose on mild steel in acidic condition. Carbohydr Polym 150:13-20. 
Shainy KM, Rugmini Ammal P, Unni KN, et al (2016) Surface Interaction and Corrosion Inhibition of Mild Steel in Hydrochloric Acid Using Pyoverdine, an Eco-Friendly Bio-molecule. J Bio- Tribo-Corrosion 2:112. https://doi.org/10.1007/s40735-016-0050-3

Sherif ESM (2014) The Role of Corrosion Inhibitors in Protecting Metallic Structures against Corrosion in Harsh Environments. Elsevier B.V.

Singh A, Ansari KR, Quraishi MA, Lgaz H (2018) Effect of electron donating functional groups on corrosion inhibition of J55 steel in a sweet corrosive environment: Experimental, density functional theory, and molecular dynamic simulation. Materials (Basel) 12:. https://doi.org/10.3390/ma12010017

Singh A, Ituen EB, Ansari KR, et al (2019) Surface protection of X80 steel using Epimedium extract and its iodide-modified composites in simulated acid wash solution: A greener approach towards corrosion inhibition. New J Chem 43:8527-8538. https://doi.org/10.1039/c9nj01691k

Sliem MH, Afifi M, Bahgat Radwan A, et al (2019) AEO7 Surfactant as an Eco-Friendly Corrosion Inhibitor for Carbon Steel in $\mathrm{HCl}$ solution. Sci Rep 9:1-16. https://doi.org/10.1038/s41598-018-37254-7

Solmaz R (2014) Investigation of adsorption and corrosion inhibition of mild steel in hydrochloric acid solution by 5-(4-Dimethylaminobenzylidene)rhodanine. Corros Sci 79:169-176. https://doi.org/10.1016/j.corsci.2013.11.001

Solomon MM, Gerengi H, Umoren SA (2017) Carboxymethyl Cellulose/Silver Nanoparticles Composite: Synthesis, Characterization and Application as a Benign Corrosion Inhibitor for St37 Steel in 15\% H2SO4 Medium. ACS Appl Mater Interfaces 9:6376-6389. https://doi.org/10.1021/acsami.6b14153

Solomon MM, Umoren SA, Udosoro II, Udoh AP (2010) Inhibitive and adsorption behaviour of carboxymethyl cellulose on mild steel corrosion in sulphuric acid solution. Corros Sci 52:1317-1325. https://doi.org/10.1016/j.corsci.2009.11.041

Subramanian B, Maruthamuthu S, Rajan ST (2015) Biocompatibility evaluation of sputtered zirconium-based thin film metallic glass-coated steels. Int J Nanomedicine 10:17-29. https://doi.org/10.2147/IJN.S79977

Sun H, Jin Z, Yang C, et al (2016) COMPASS II: extended coverage for polymer and drug-like molecule databases. J Mol Model 22:1-10. https://doi.org/10.1007/s00894-016-2909-0

Thaçi V, Hoti R, Berisha A, Bogdanov J (2020) Corrosion study of copper in aqueous sulfuric acid solution in the presence of (2E,5E)-2,5-dibenzylidenecyclopentanone and (2E,5E)-bis[(4dimethylamino)benzylidene]cyclopentanone: Experimental and theoretical study. Open Chem 18:14121420. https://doi.org/10.1515/chem-2020-0172

Umoren SA, AlAhmary AA, Gasem ZM, Solomon MM (2018) Evaluation of chitosan and carboxymethyl cellulose as ecofriendly corrosion inhibitors for steel. Int J Biol Macromol 117:1017-1028. https://doi.org/10.1016/j.ijbiomac.2018.06.014 
Umoren SA, Banera MJ, Alonso-Garcia T, et al (2013) Inhibition of mild steel corrosion in HCl solution using chitosan. Cellulose 20:2529-2545. https://doi.org/10.1007/s10570-013-0021-5

Umoren SA, Obot IB, Madhankumar A, Gasem ZM (2015) Performance evaluation of pectin as ecofriendly corrosion inhibitor for X60 pipeline steel in acid medium: Experimental and theoretical approaches. Carbohydr Polym 124:280-291. https://doi.org/10.1016/j.carbpol.2015.02.036

V V Sher and Voevoda Comparative study of the anti oxidant and anti corrosion properties of metal dialkyl and diaryldithiophosphates. Chem Technol Fuels Oils 5:305-307

Vorobyova VI, Skiba MI, Shakun AS, Nahirniak S V. (2019) Relationship between the inhibition and antioxidant properties of the plant and biomass wastes extracts - A Review. Int J Corros Scale Inhib 8:150-178. https://doi.org/10.17675/2305-6894-2019-8-2-1

Waanders FB, Vorster SW, Geldenhuys AJ (2002) Biopolymer corrosion inhibition of mild steel: Electrochemical/Mössbauer results. Hyperfine Interact 139-140:133-139. https://doi.org/10.1023/A:1021271005989

Woranuch S, Yoksan R (2013) Preparation, characterization and antioxidant property of water-soluble ferulic acid grafted chitosan. Carbohydr Polym 96:495-502. https://doi.org/10.1016/j.carbpol.2013.04.006

Xu S, Zhang S, Guo L, et al (2019) Experimental and theoretical studies on the corrosion inhibition of carbon steel by two indazole derivatives in $\mathrm{HCl}$ medium. Materials (Basel) 12:1-11. https://doi.org/10.3390/ma12081339

Xu X, Singh A, Sun Z, et al (2017) Theoretical, thermodynamic and electrochemical analysis of biotin drug as an impending corrosion inhibitor for mild steel in $15 \%$ hydrochloric acid. R Soc Open Sci 4 :. https://doi.org/10.1098/rsos.170933

Xu Y, Zhang S, Li W, et al (2018) Experimental and theoretical investigations of some pyrazolo-pyrimidine derivatives as corrosion inhibitors on copper in sulfuric acid solution. Appl Surf Sci 459:612-620. https://doi.org/10.1016/j.apsusc.2018.08.037

Yildiz R (2015) An electrochemical and theoretical evaluation of 4,6-diamino-2-pyrimidinethiol as a corrosion inhibitor for mild steel in $\mathrm{HCl}$ solutions. Corros Sci 90:544-553. https://doi.org/10.1016/j.corsci.2014.10.047

Zhang HH, Qin CK, Chen Y, Zhang Z (2019a) Inhibition behaviour of mild steel by three new benzaldehyde thiosemicarbazone derivatives in 0.5 M H 2 SO 4 : experimental and computational study . R Soc Open Sci 6:190192. https://doi.org/10.1098/rsos.190192

Zhang W, Li HJ, Wang M, et al (2019b) Highly effective inhibition of mild steel corrosion in $\mathrm{HCl}$ solution by using pyrido[1,2-a]benzimidazoles. New J Chem 43:413-426. https://doi.org/10.1039/C8NJ04028A

Zulhusni MDM, Othman NK, Lazim AM (2015) Enhancement of corrosion resistance of carbon steel by Dioscorea Hispida starch in NaCl. AIP Conf Proc 1678:. https://doi.org/10.1063/1.4931277 
Figures

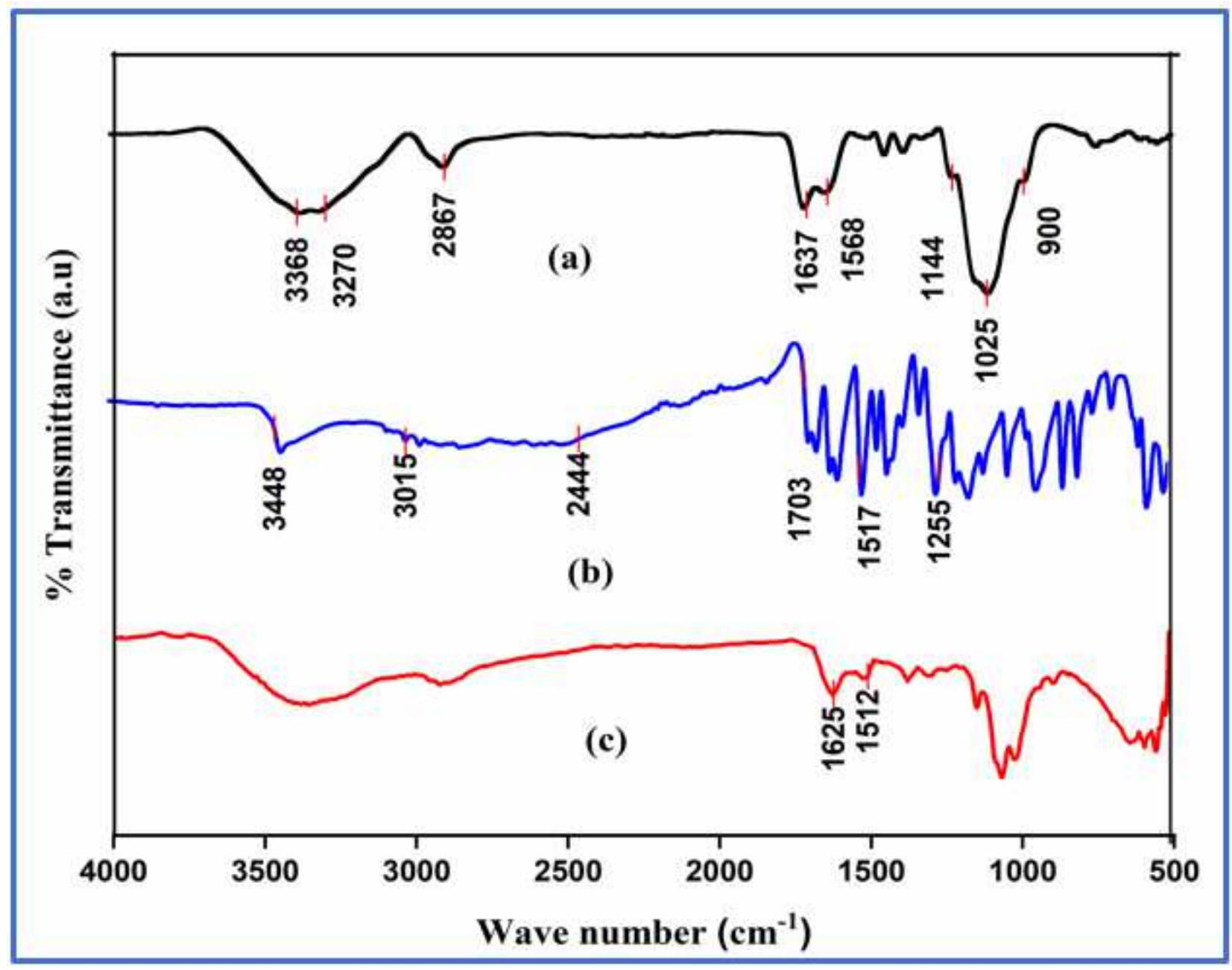

Figure 1

Comparative IR spectrum of (a) Chitosan biopolymer (b) Ferulic acid and (c) FCS 


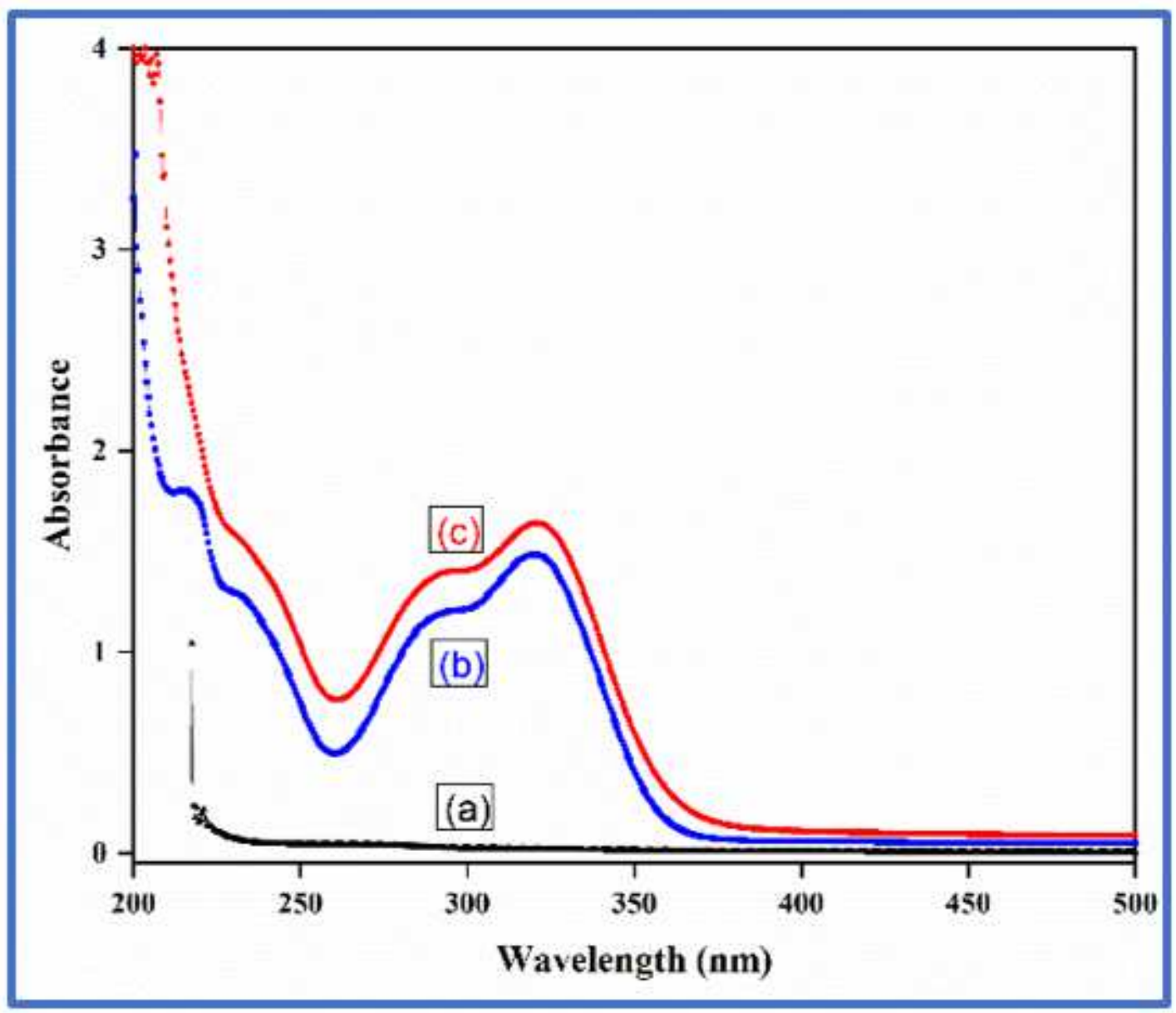

Figure 2

Comparative UV spectrum of (a) Chitosan, (b) Ferulic acid, and (c) FCS 


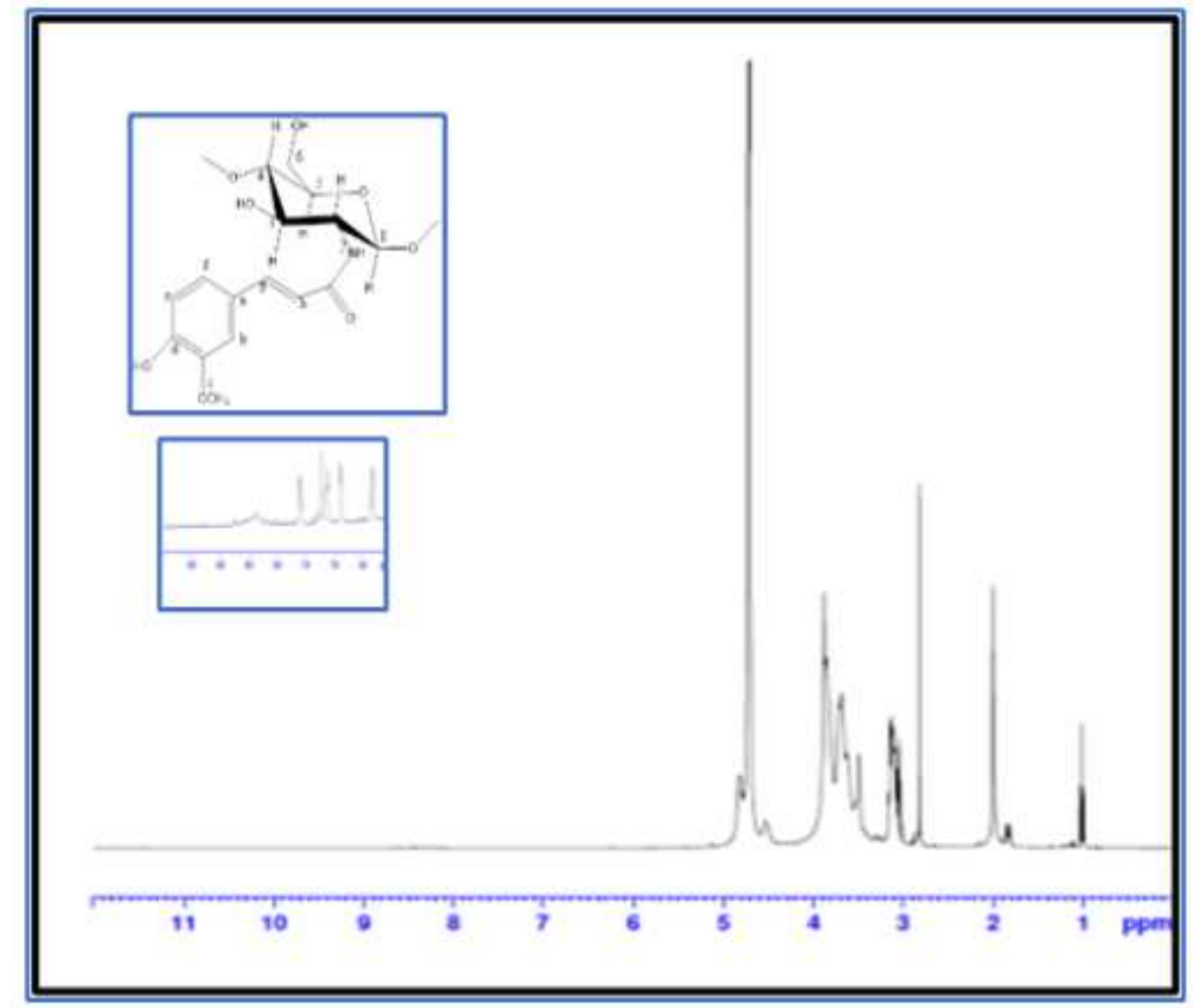

Figure 3

NMR spectrum of FCS inhibitor
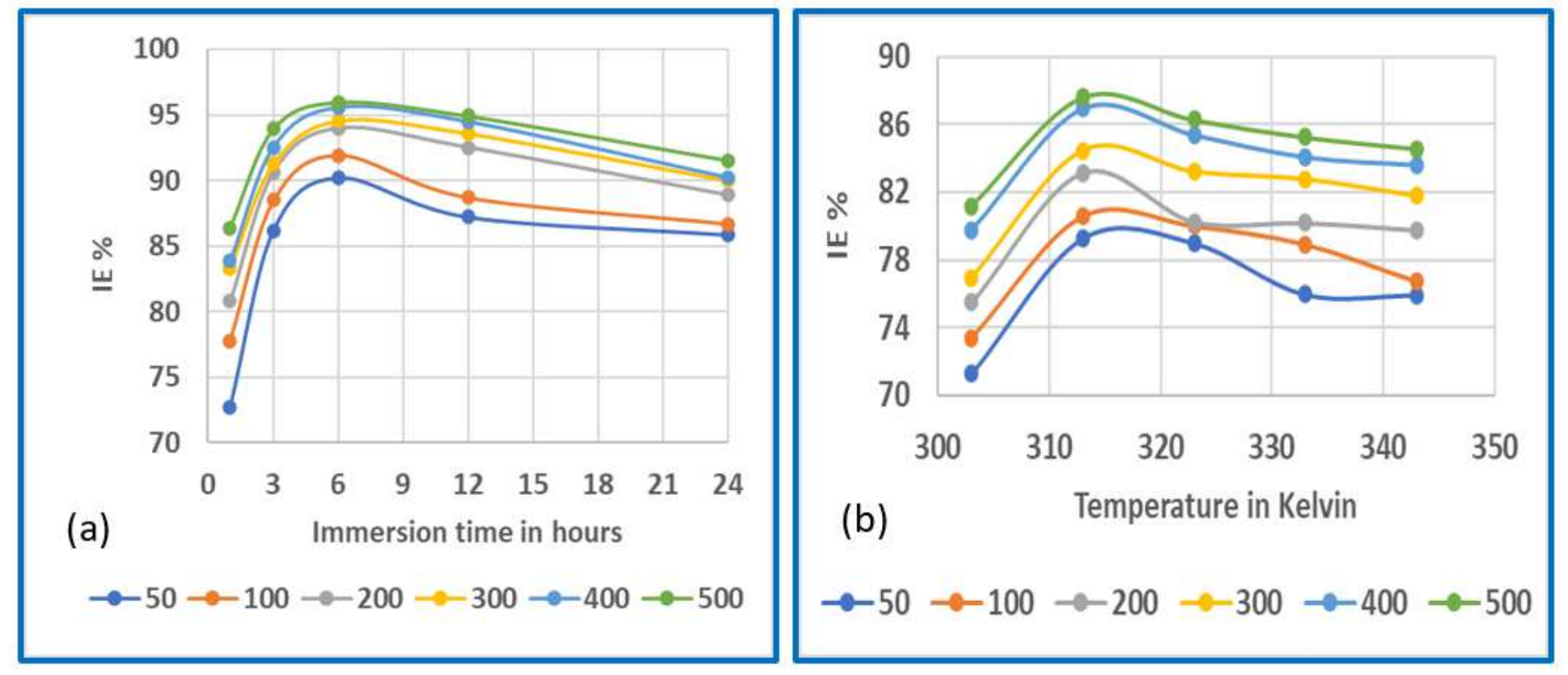

Figure 4

Change in corrosion inhibition performance of FCS for mild steel in $1 \mathrm{M} \mathrm{HCl}$ at various (a) immersion periods (b) temperatures 


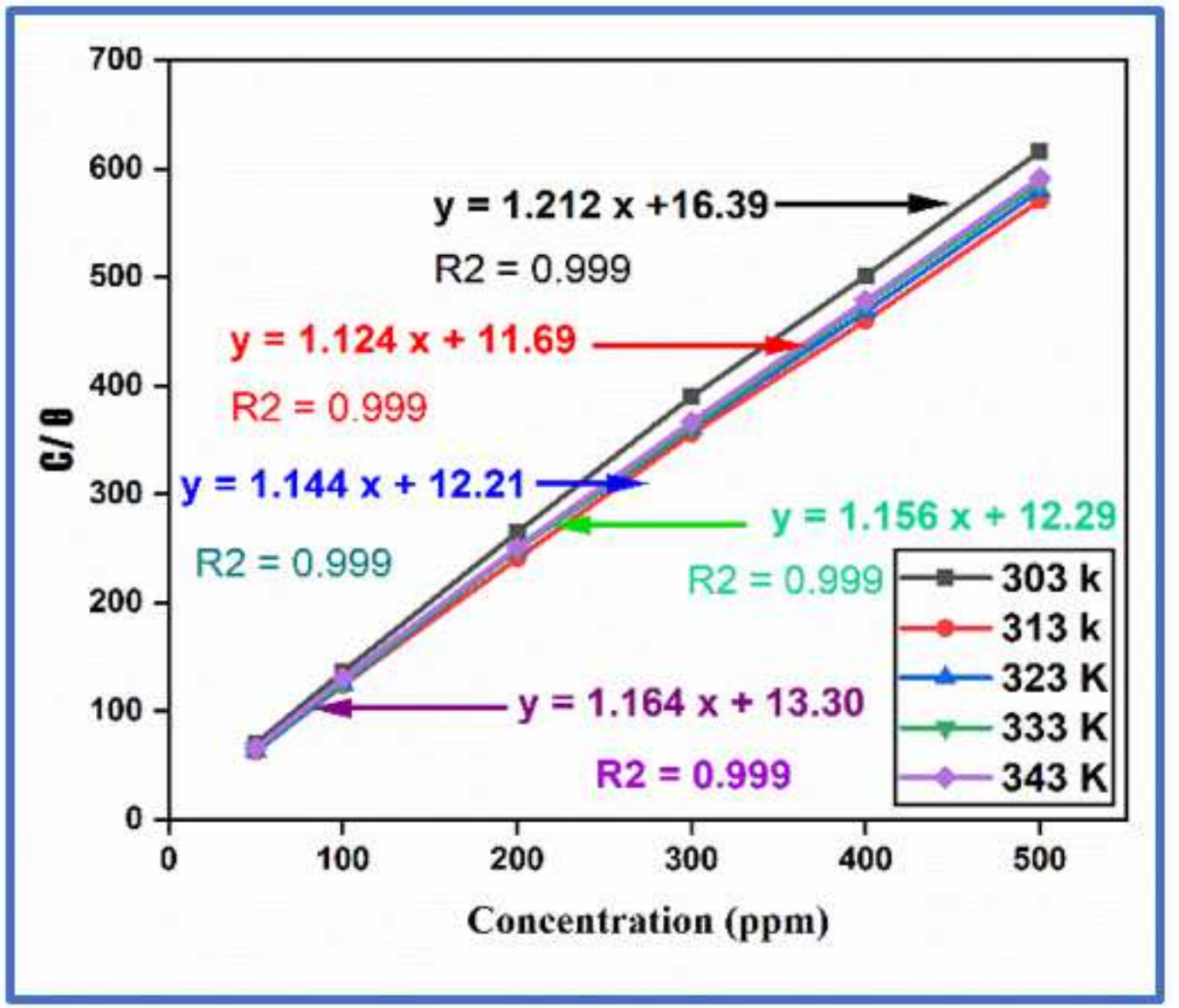

Figure 5

Langmuir isotherm plot for mild steel in $1 \mathrm{M} \mathrm{HCl}$ without and with FCS 


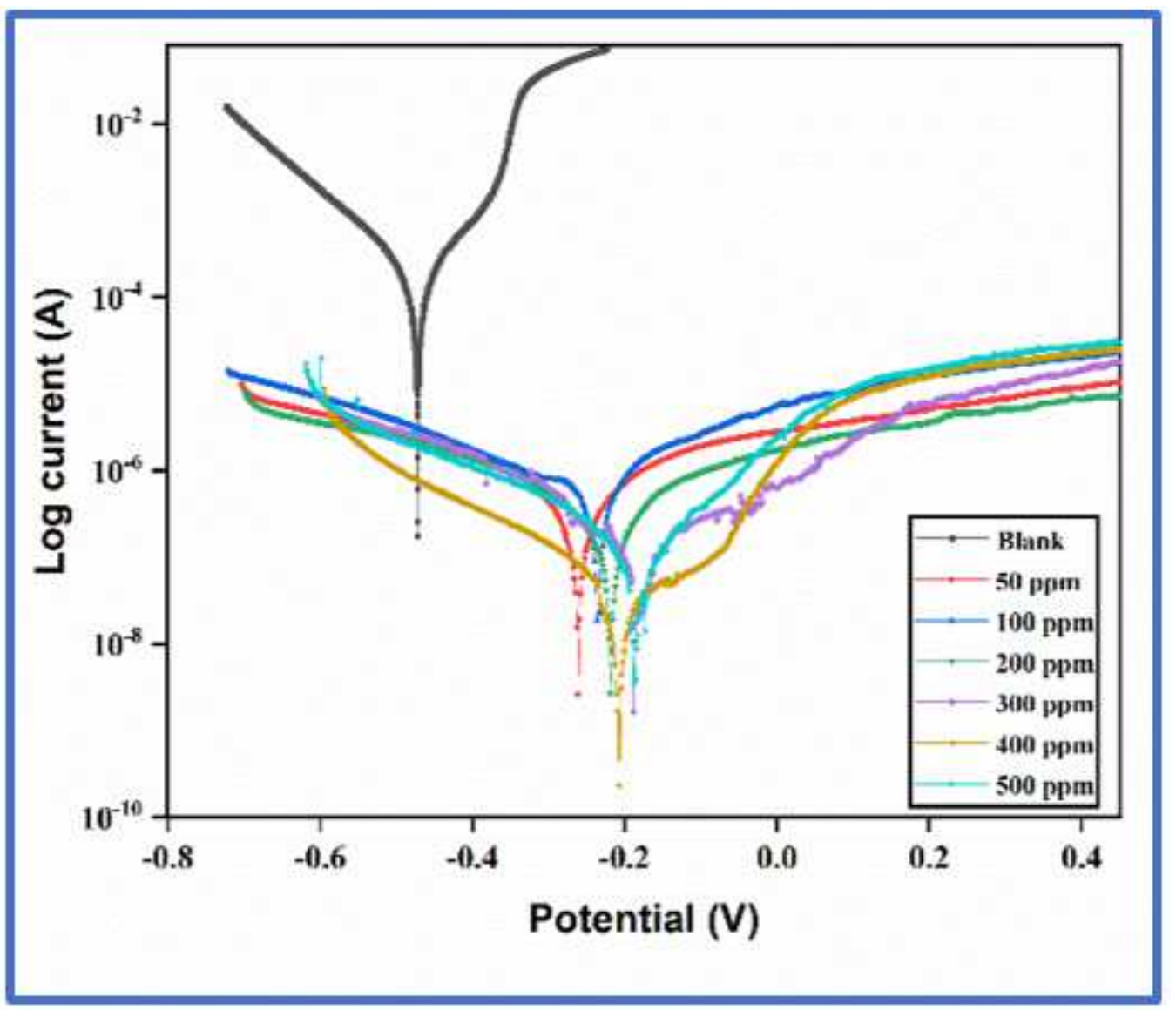

Figure 6

Tafel plot for mild steel in $1 \mathrm{M} \mathrm{HCl}$ with and without FCS
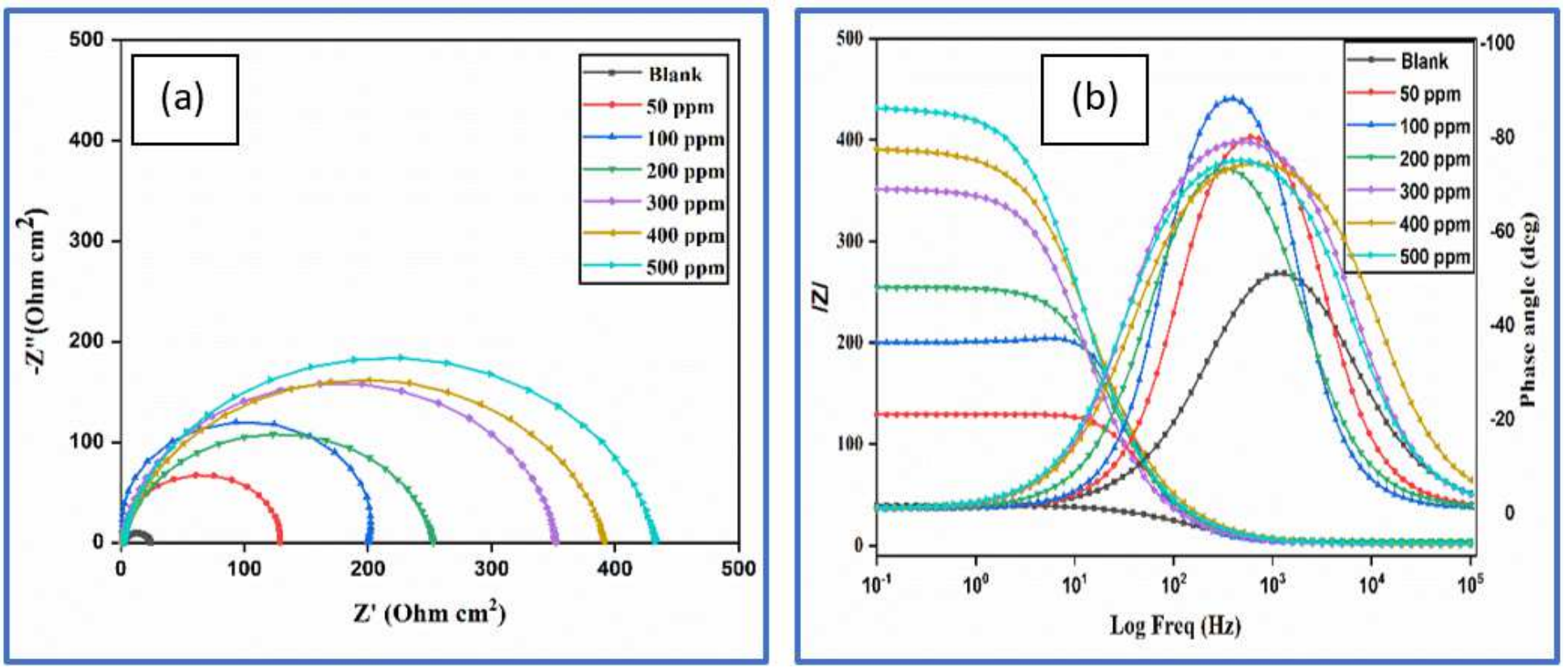

Figure 7

(a) Nyquist plot (b) Bodes, phase angle plots for mild steel in $1 \mathrm{M} \mathrm{HCl}$ without and with FCS inhibitor at $303 \mathrm{~K}$ 


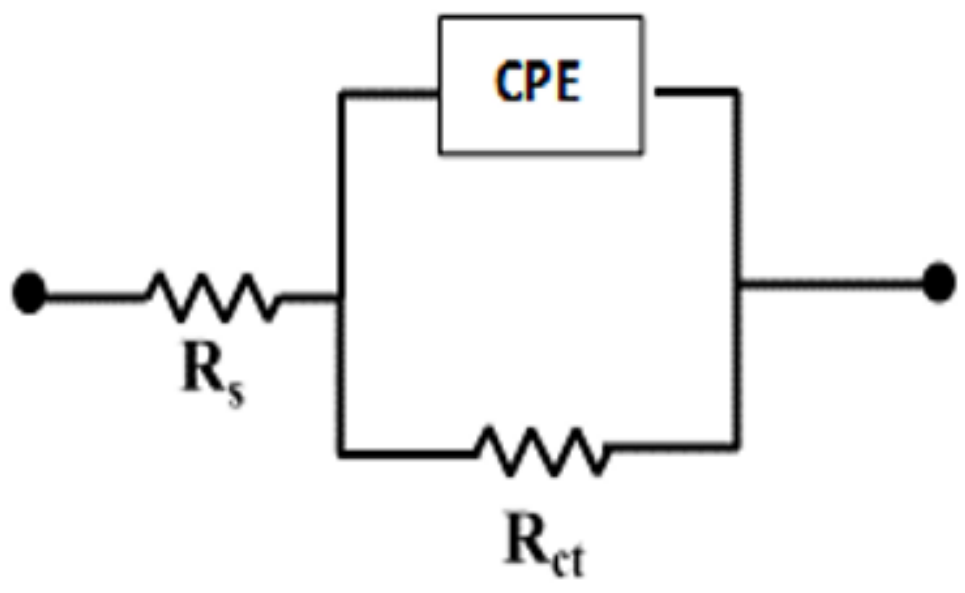

Figure 8

Equivalent circuit
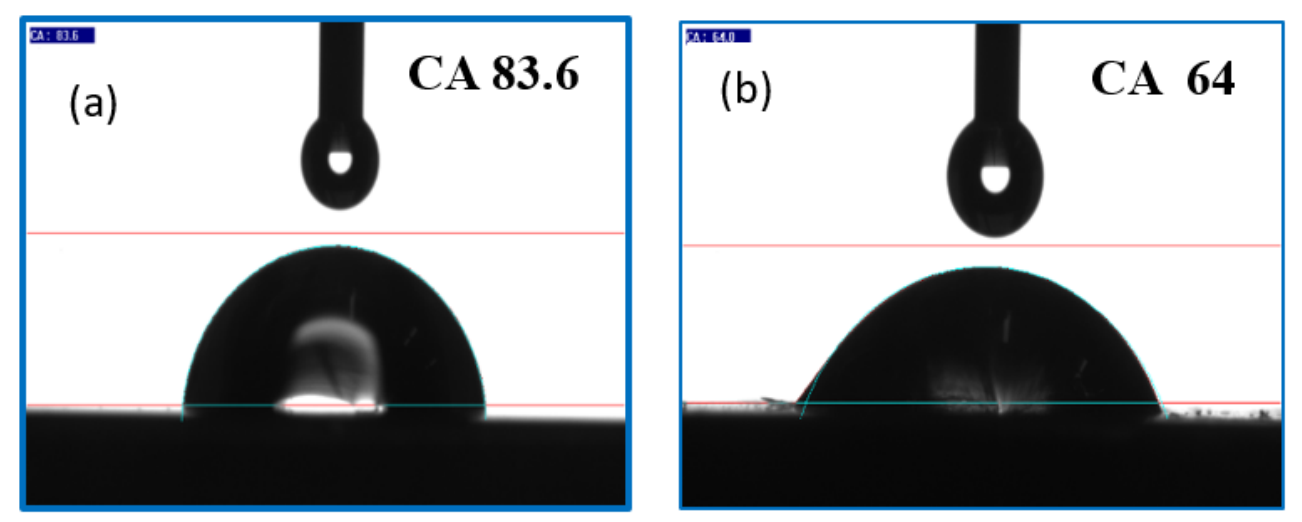

\begin{tabular}{|l|l|}
\hline (c) & CA 97.6 \\
\hline & \\
\hline
\end{tabular}

Figure 9

Contact angle of mild steel surfaces (a) plain (b) exposed to acid (c) exposed to acid containing the FCS inhibitor
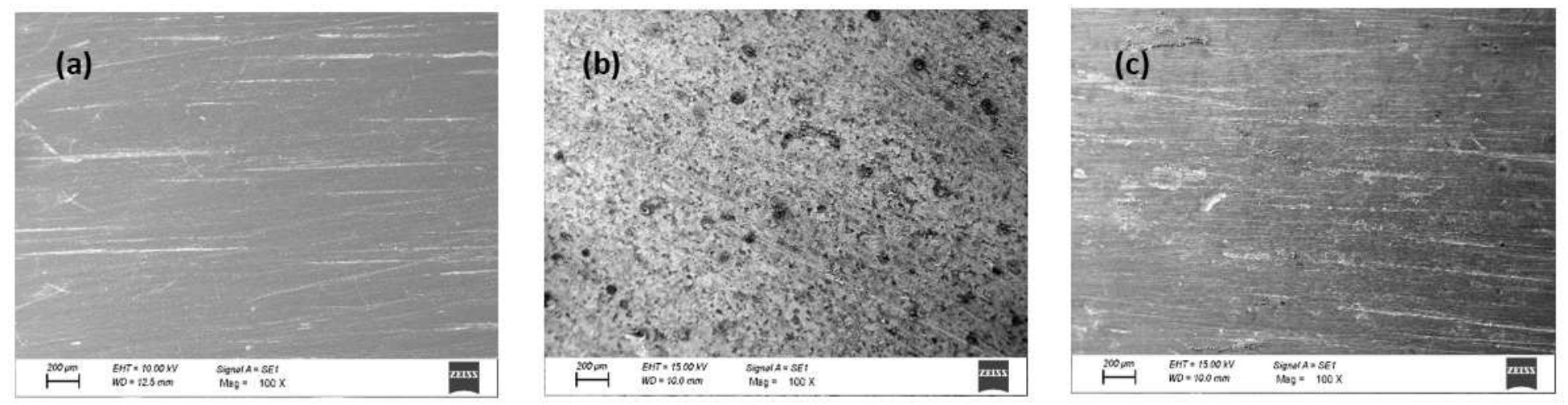

Figure 10

SEM image of the mild steel surfaces (a) plain (b) exposed to acid (c) exposed to acid containing FCS 

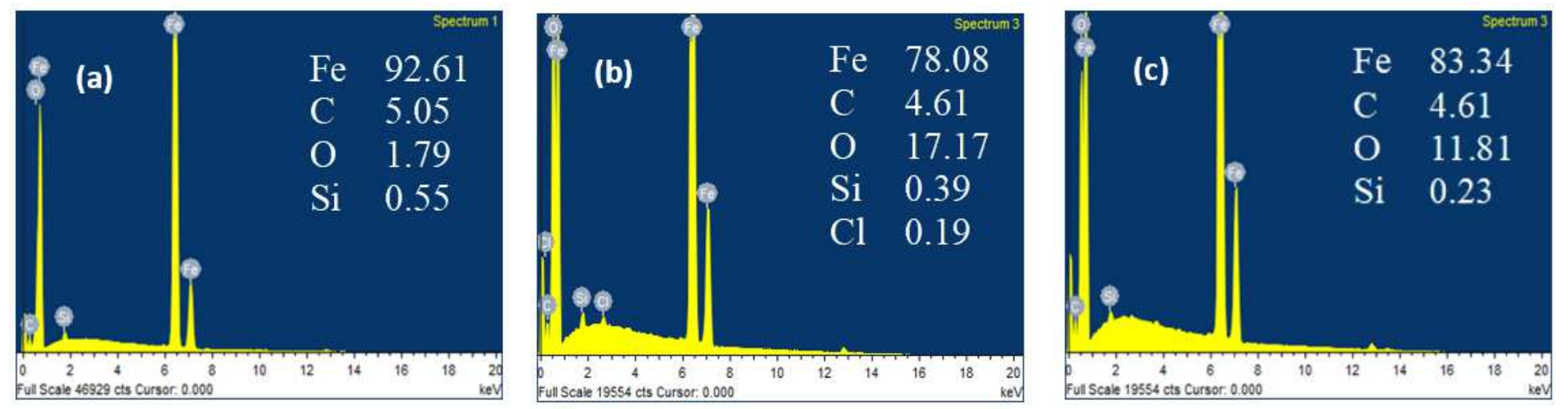

Figure 11

EDAX image of surfaces (a) plain metal (b) exposed to $1 \mathrm{M} \mathrm{HCl}$ (c) exposed to $1 \mathrm{M} \mathrm{HCl}$ containing FCS

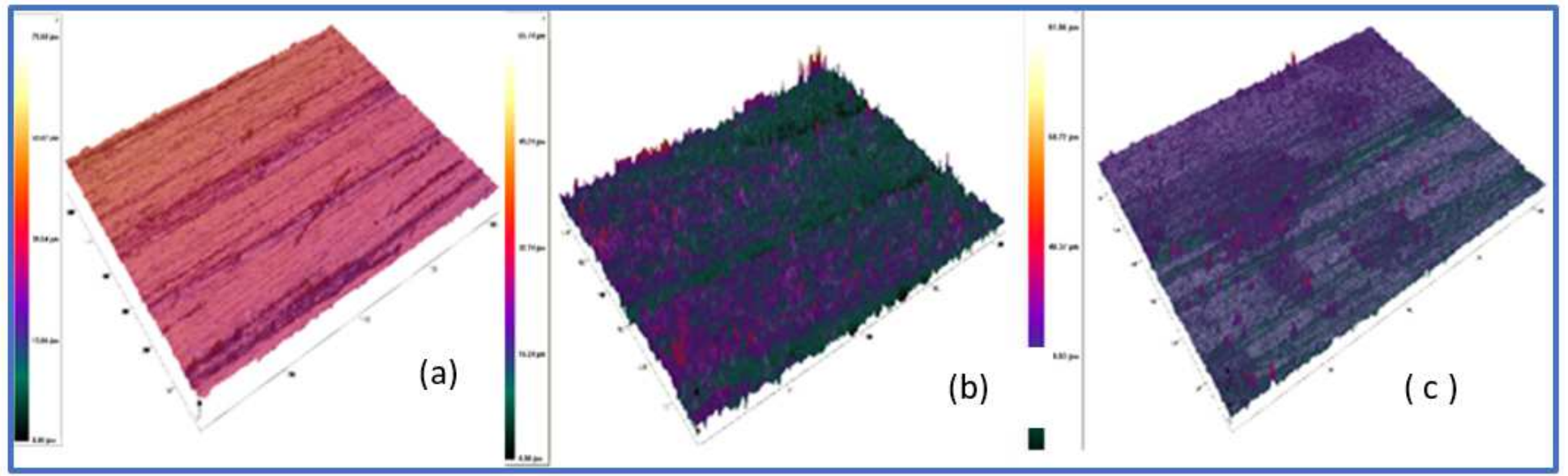

\section{Figure 12}

3D images of mild steel surfaces (a) Plain metal (b) exposed to acid and (c) exposed to acid containing FCS
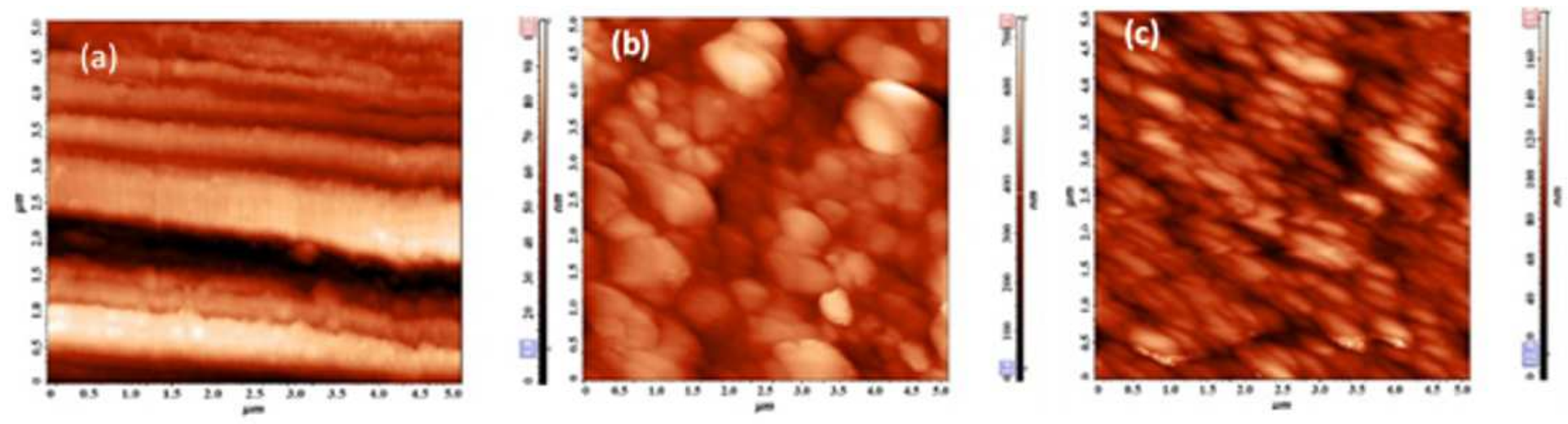

Figure 13

AFM (2 D) image of surfaces (a) plain metal (b) exposed to $1 \mathrm{M} \mathrm{HCl}$ and (c) exposed to $1 \mathrm{M} \mathrm{HCl}$ containing FCS 

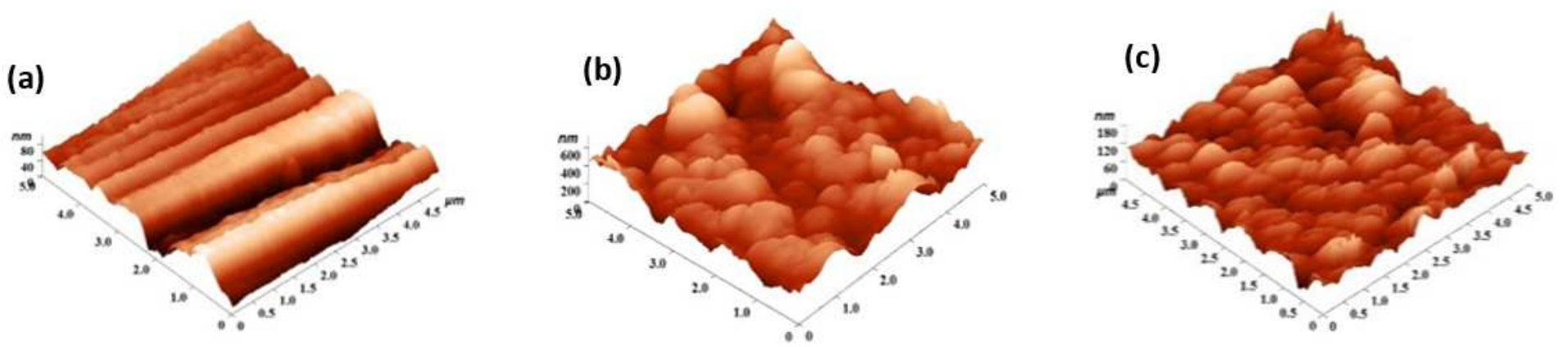

Figure 14

AFM (3 D) images of surfaces (a) plain metal (b) exposed to $1 \mathrm{M} \mathrm{HCl}$ and (c) exposed to $1 \mathrm{M} \mathrm{HCl}$ containing FCS

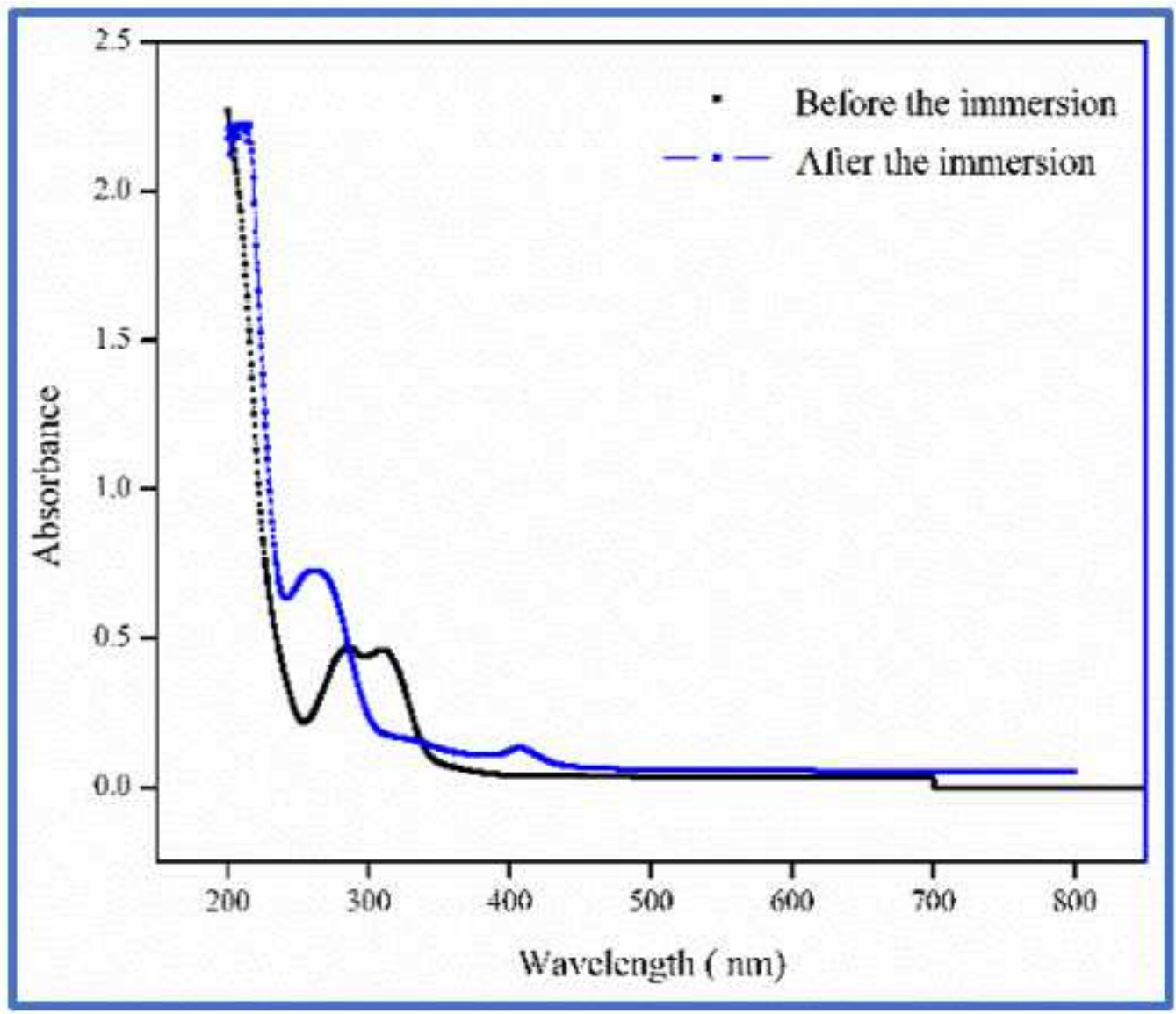

Figure 15

UV-visible spectra of FCS solution before and after introducing the mild steel samples 


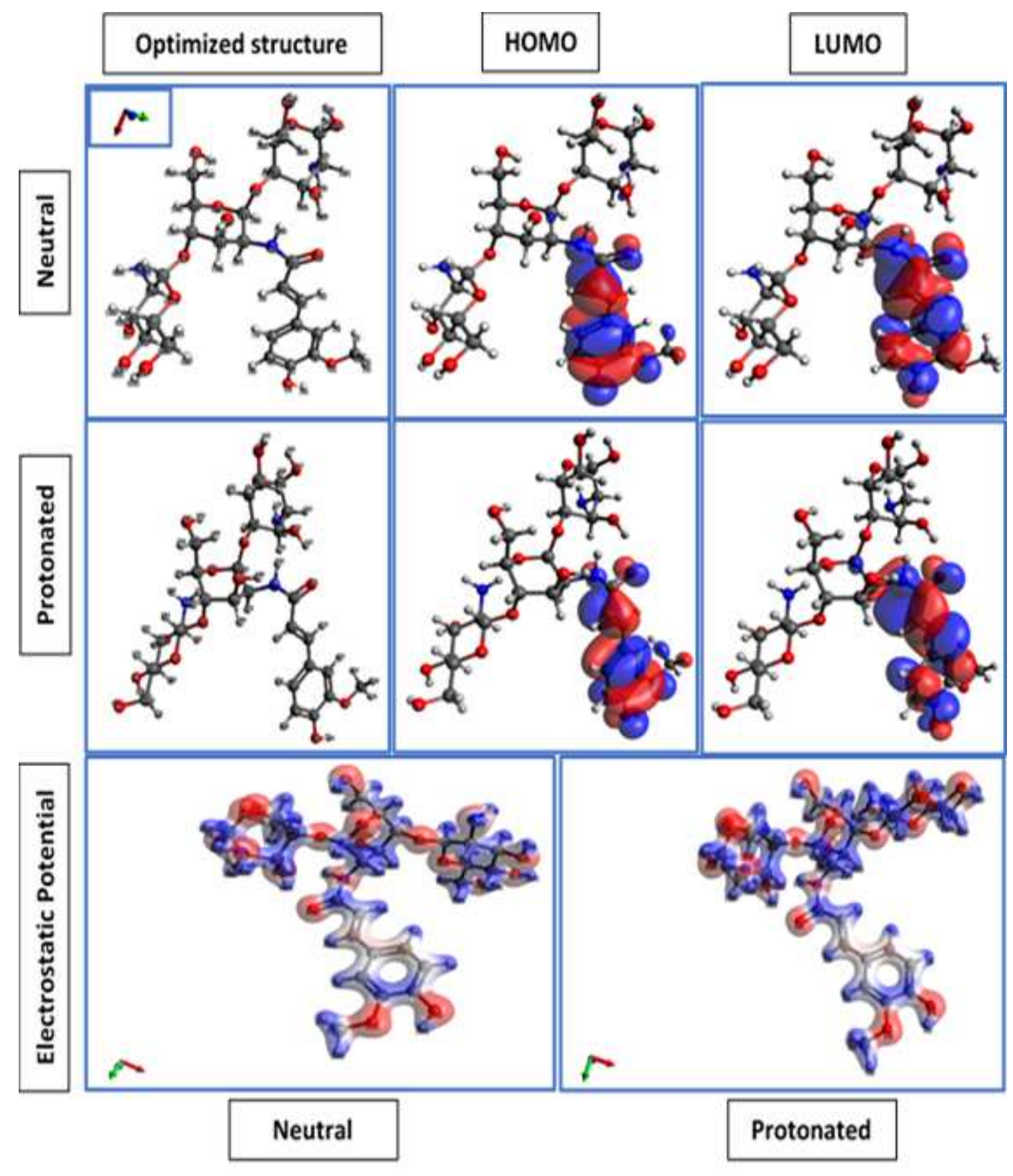

Figure 16

UV-visible spectra of FCS solution before and after introducing the mild steel samples 


\section{\begin{tabular}{l|l} 
FCS & FCS- $\mathrm{H}^{+}$ \\
\hline
\end{tabular}}

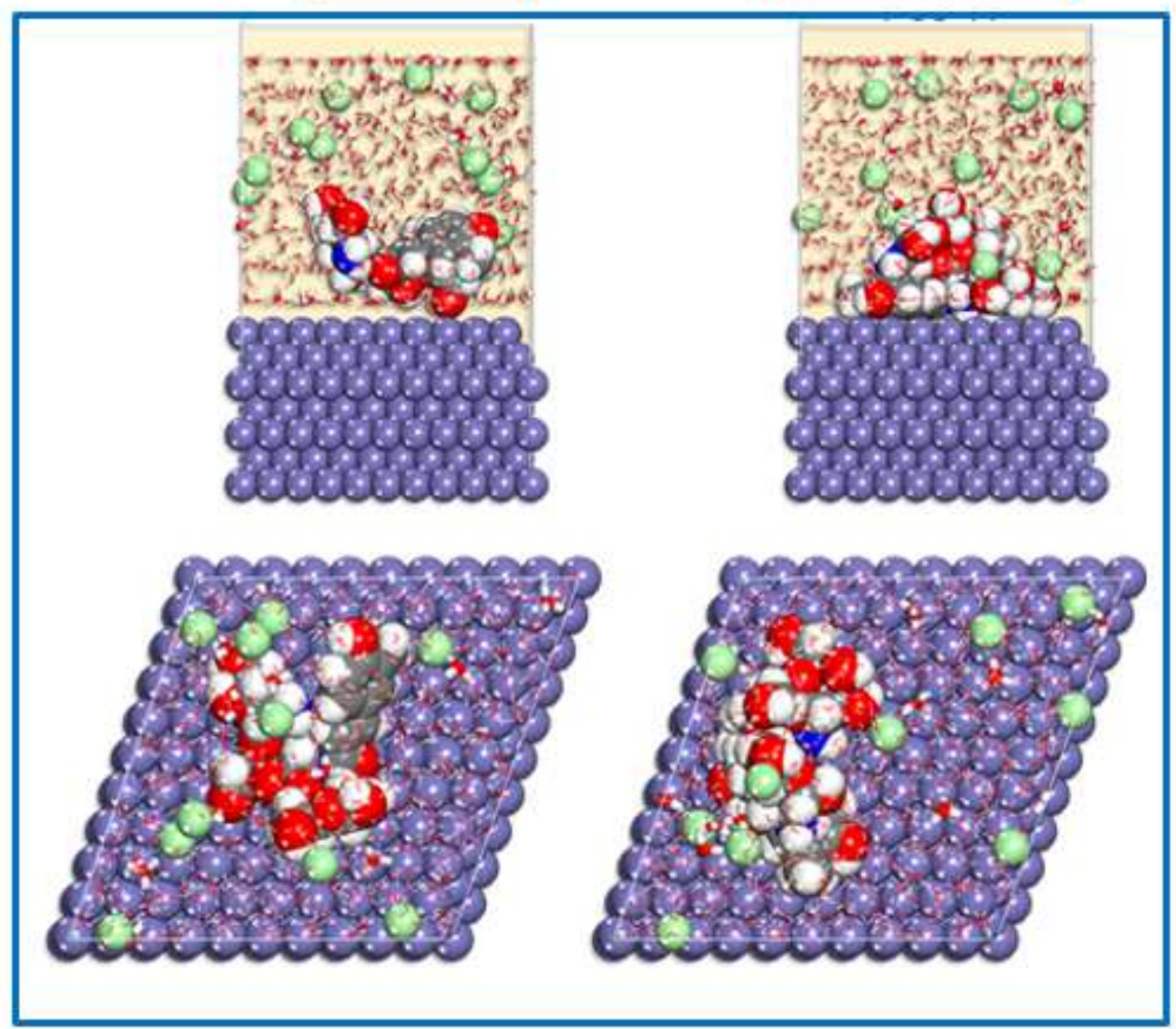

\section{Figure 17}

MC poses the lowest adsorption configurations for the FCS and FCS-H+ in the simulated corrosion media on the Fe (1 110$)$ surface 


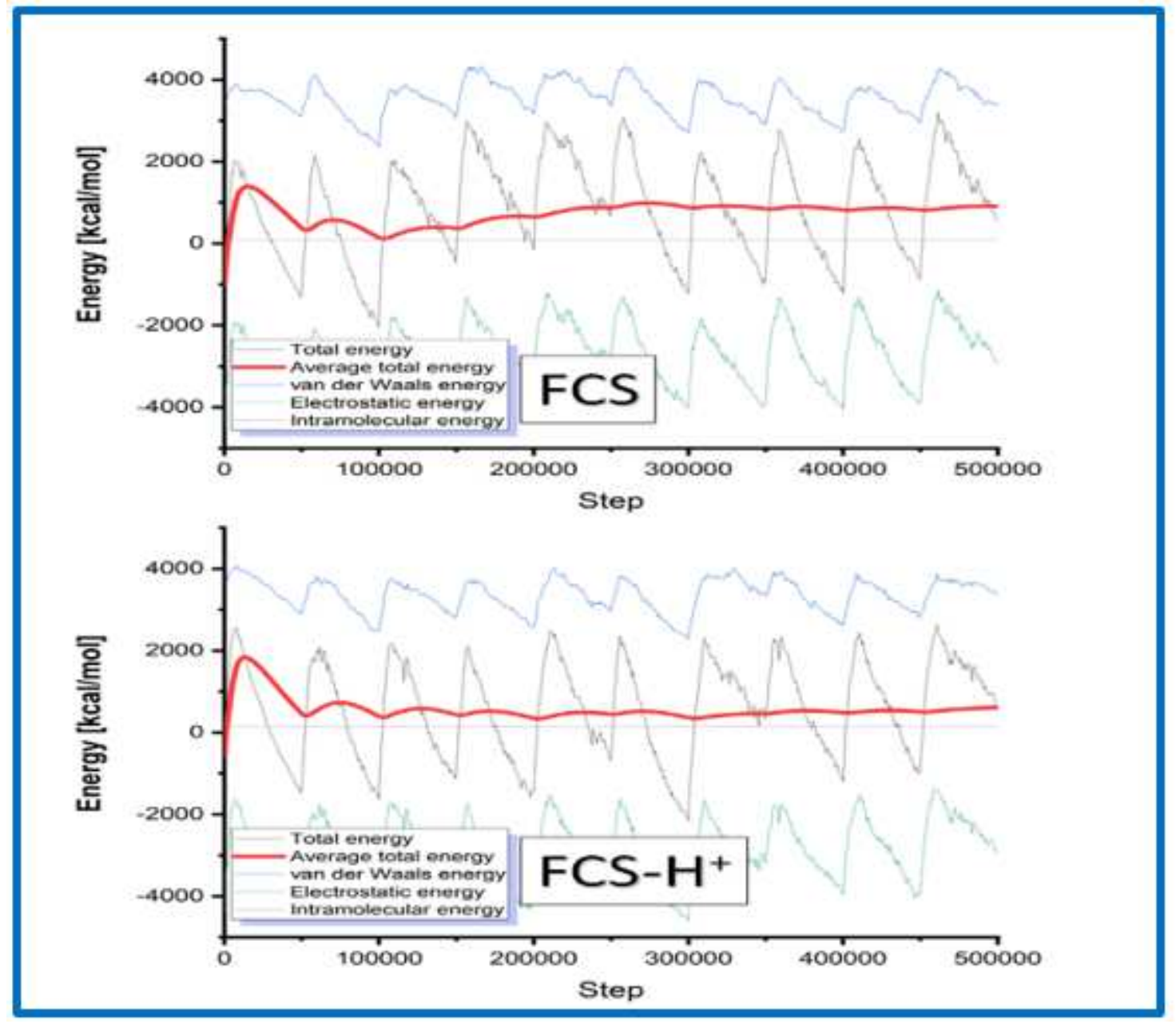

\section{Figure 18}

The presentation of the different energy terms contributions during the Monte Carlo calculations for FCS (neutral) and FCS-H+ (protonated) inhibitor molecule 


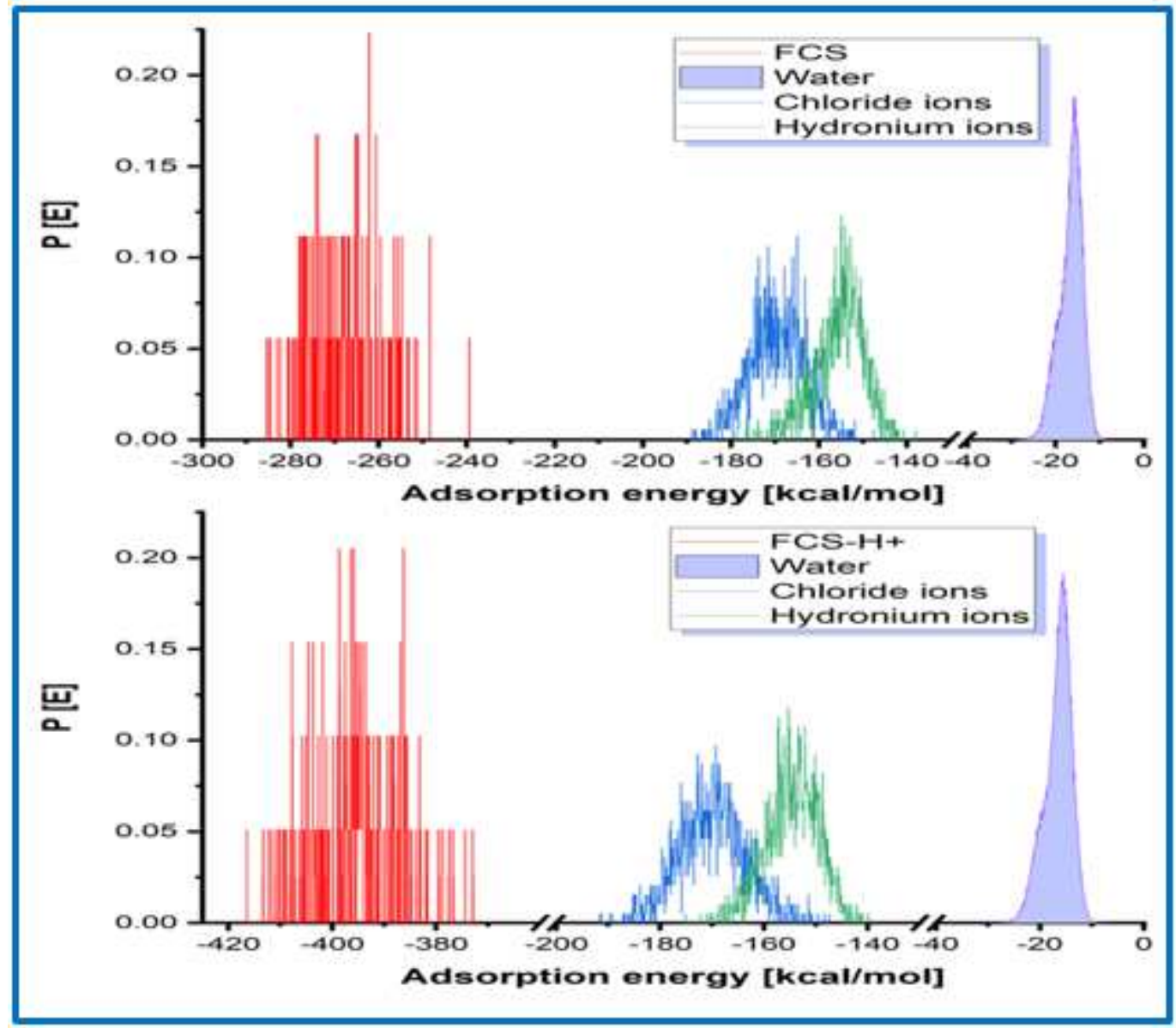

Figure 19

Distribution of adsorption energies for: FCS (neutral) and FCS-H+ (protonated) inhibitor onto the Fe(110) surface 


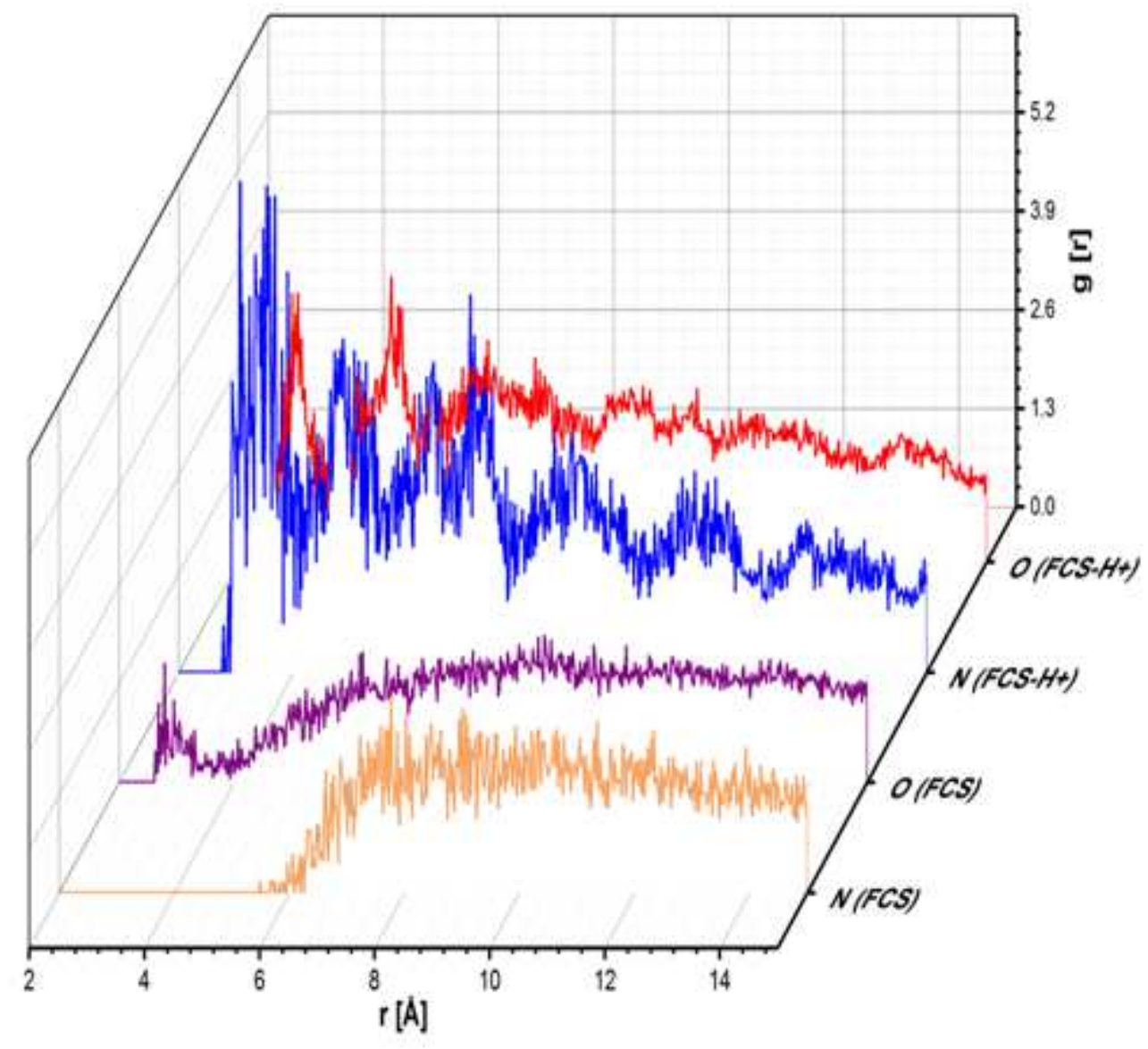

Figure 21

RDF of heteroatoms (nitrogen and oxygen,) for FCS and FCS-H+ on the Fe surface obtained from MD trajectory

\section{Supplementary Files}

This is a list of supplementary files associated with this preprint. Click to download.

- GA.png

- Supplementaryinformation.docx 